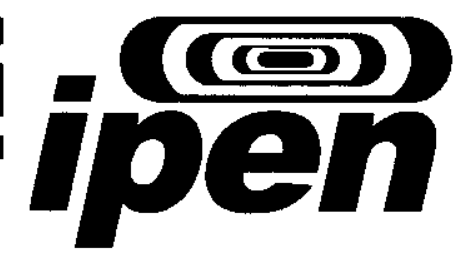

AUTARQUIA ASSOCIADA À UNIVERSIDADE DE SÃO PAULO

\title{
OBTENÇÃO DE FRITAS VITROCERÂMICAS A PARTIR DE RESÍDUOS SÓLIDOS INDUSTRIAIS
}

\author{
MATHEUS CHIANCA FERREIRA
}

Dissertação apresentada como parte dos requisitos para obtenção do Grau de Mestre em Ciências na Área de Tecnologia Nuclear - Materiais.

Orientadora:

Dra. Sonia R. Homem de Mello Castanho

São Paulo

2006 


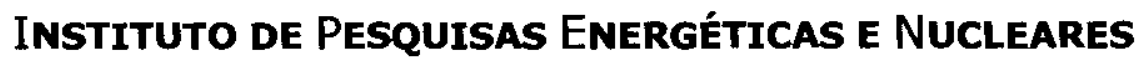
Autarquia Associada à Universidade de São Paulo

\title{
Obtenção de fritas Vitrocerâmicas a Partir de
}

\section{RESÍDUOS SóLIDOS INDUSTRIAIS}

\author{
Matheus Chianca Ferreira
}

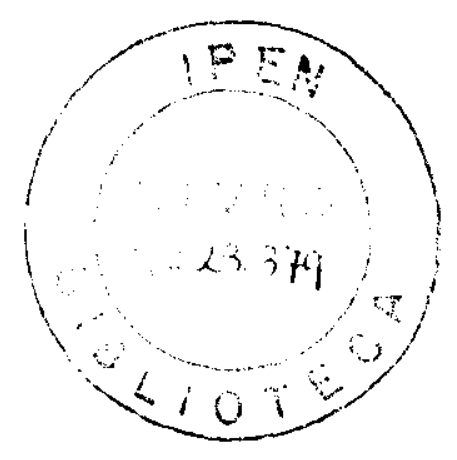

Dissertação apresentada como parte dos requisitos para obtenção do Grau de Mestre em Ciências na Área de Tecnologia Nuclear - Materiais

Orientadora:

Dra. Sonia R. Homem de Mello Castanho

\section{São Paulo}

2006 


\section{DEDICATÓRIA}

Dedico este trabalho à minha família pela importância que eles têm em minha vida, dando apoio quando mais precisei deles. A base de tudo. 


\section{AGRADECIMENTOS}

Ao IPEN pela oportunidade de realização deste trabalho.

A Dra. Sonia R. Homem de Mello Castanho pela orientação, apoio, amizade, dedicação e conselhos durante os anos como aluno de pósgraduação.

Ao Dr. Antonio Carlos Cruz por ter-nos cedido o resíduo, objeto de estudo deste trabalho.

A Dra. Pilar Pena por ter realizado as caracterizações na frita cerâmica.

Ao técnico Rene Olivier e Dr. Nelson B. Lima pela amizade e tempo desprendido nas análises realizadas no laboratório de DRX.

Ao técnico Celso Morais pelo tempo desprendido nas análises realizadas no laboratório de MEV.

Ao Dr. Luis Gallego Martinez pela ajuda em alguns difratogramas.

A minha namorada por toda a paciência que ela soube ter comigo nesta etapa final de desenvolvimento do trabalho.

Aos amigos dos laboratórios de Insumos e Reologia: Chieko, Joana, Kenji, Sandra e Valter pelo auxílio, colaboração e pronto atendimento. E amigos que passaram e deixaram marcas na "Casa da Árvore" Amanda, André, A. C., Camila, Chiba, Deiby, Eduardo "X", Egberto, Lílian, Luiz, Marcão, Raissa, Raniere, Reinaldo, Sandra, Tammy, Thaís e Thiago pelas discussões, convivência, amizade e risadas. 
E a todos os amigos, que de maneira geral contribuíram direta ou indiretamente para que este trabalho se tornasse real e verdadeiro. 


\title{
Obtenção de Fritas VItrocerâmicas a partir de RESÍDUOS SólIDOS INDUSTRIAIS
}

\author{
Matheus Chianca Ferreira
}

\section{Resumo}

O resíduo estudado neste trabalho é originado do processo de obtenção de alumínio metálico, de grande interesse no Brasil pelo fato do país ser detentor de algumas das maiores reservas do mineral bauxita no mundo, utilizado como fonte de alumínio. Tendo como estratégia a geração de resíduo zero, colaborando para as tecnologias ambientalmente amigáveis, este trabalho estuda a incorporação de um resíduo resultante da recuperação de alumínio presente na escória gerada durante o processo de produção primária do alumínio metálico, por plasma térmico. Utilizando-se o diagrama de equilíbrio de fases do sistema $\mathrm{Al}_{2} \mathrm{O}_{3}-\mathrm{CaO}-\mathrm{SiO}_{2}$, fez-se a adequação das composições visando a incorporação de resíduo no produto cerâmico sem alterar as características de processamento do material. A obtenção de vidros e de fritas vitrocerâmicas com o resíduo borra branca foi realizada fazendo-se a fusão das composições calculadas e, para os vitrocerâmicos, tratamento térmico posterior de devitrificação. Os produtos obtidos foram caracterizados utilizando-se técnicas de análise tais como difração de raios $X$ (DRX), microscopia eletrônica de varredura (MEV) e espectroscopia do infravermelho (FTIR). Foi possível obter material vitrocerâmico com até 30\% de resíduo de alumínio, após a fusão a $1300^{\circ} \mathrm{C}$ e devitrificação a $900^{\circ} \mathrm{C}$. Em adição, o resíduo demonstrou ser um promissor material auxiliar na formação de fases cristalinas em baixos tempos de tratamento térmico. 


\title{
GLASSCERAMICS FRITS ATTAINMENT FROM INDUSTRIAL SOLID WASTES
}

\author{
Matheus Chianca Ferreira
}

\begin{abstract}
This work study the residue obtained from the process of aluminum metal extraction activities, a great interest process, because of Brazil own some of the biggest bauxite mineral reserves in all the world. As a useful choice for no residue generation, and a support for environmentaly friendly technologies, this work studies the white dross residue (WDR), from the process of aluminum metal reduction by thermal plasma. The phase equilibrium diagram of $\mathrm{Al}_{2} \mathrm{O}_{3}-\mathrm{CaO}-\mathrm{SiO}_{2}$ system was used to calculate the compositions. The WDR were incorporated in a ceramic product without modifying its principal characteristics. The fusion and devitrification treatments were studied. XRD (X-ray diffractometry), SEM (scanning electron microscopy) and FIIR (transformed Fourier infrared) were used to investigate the glass and glasscercamic samples. These tecniques showed that is possible to get glassceramic with up to 30 mass\% of WDR after molten at $1300^{\circ} \mathrm{C}$ and annealed at $900^{\circ} \mathrm{C}$. In addition, the WDR showed to be a promising material in attainment of crystalline phases in less times of heat treatment for annealling.
\end{abstract}




\section{SUMARIO}

Item

1

2

3

3.1

3.2

3.3

3.4

3.5

3.6

3.7

3.8

3.9

4

4.1

4.1.1

4.1.2

4.2

4.2.1

4.2 .2

4.2 .3

4.2.4

4.2.5

4.2.6

4.2 .7

4.2.8

4.3

4.3.1

4.3.2

4.3.3

INTRODUÇÃO

Pag.;

01

OBJETIVO

03

REVISÃO DA LITERATURA

04

A Indústria Mineral no Brasil 04

Bauxita 04

Processo Bayer $\quad 05$

Aluminio $\quad 08$

Resíduos no Brasil $\quad 10$

Residuos Sólidos Industriais $\quad 12$

Plasma Térmico 13

Materiais Vitrocerâmicos $\quad 14$

$\begin{array}{ll}\text { Histórico } & 17\end{array}$

MATERIAIS E MÉTODOS 22

Matérias-primas $\quad 22$

Residuo $\quad 22$

Fritas $\quad 22$

Técnicas de Análise $\quad 23$

Espectrometria por Fluorescência de Raios X-FRX 23

Espectrometria por Difração de Raios $X-D R X$

Análise Térmica Diferencial e Termogravimétrica - ATD / 23

ATG

Diâmetro médio equivalente (distribuição granulométrica

25 por dispersão a laser) - CILAS

Area de Superficie Especifica - BET

Massa Especifica Real - Picnometria de Gás Hélio - MEV /EDS

Análise por Espectrometria de Infravermelho - FTIR 26

Procedimento Experimental 27

Amostragem 27

Desagregação / Moagem 28

Formulação das Composições com adição de Resíduo 
4.3.4 Preparação das composições com adição de Resíduo 30

4.3.5 Fusão das Composições 30

4.3.6 Tratamento de Devitrificação 32

$5 \quad$ RESULTADOS E DISCUSSÃO 34

5.1 Caracterização das matérias-primas 34

5.1.1 Caracterização do Resíduo Borra Branca (RBB) 34

5.1.2 Caracterização da Frita 41

5.2 Tratamento Térmico da Frita 45

5.3 Composições da Frita com adição de Resíduo 47

$5.4 \quad$ Estudo de devitrificação 54

6 CONCLUSÕES 60

$7 \quad$ SUGESTÕES PARA TRABALHOS FUTUROS

$8 \quad$ REFERÊNCIAS BIBLIOGRÁFICAS 62 
3.1 Fluxograma simplificado do processo Bayer. 07

3.2 Esquema simplificado de uma célula de redução de 08 alumínio metálico.

4.1 Diagrama de blocos das etapas de desenvolvimento 27 experimental do trabalho.

4.2 Diagrama de equilíbrio de fases do sistema Alumina- 29 Cálcia-Sílica.

4.3 Forno Lindberg Blue/M - Blue M eletric CP 56724C. 31

4.4 Cadinhos utilizados na fusão das fritas modificadas. 31

4.5 Curva de tratamento térmico de devitrificação. 32

5.1 Aspecto do Resíduo como recebido. 34

5.2 Micrografias obtidas por MEV a partir de amostras de 35 Resíduo Borra Branca como recebido, (a) agregado de resíduo; (b) partículas que compõem os agregados.

5.3 Distribuição granulométrica do resido por CILAS. 36

5.4 Difratograma do resíduo como recebido. 37

5.5 Análise térmica do resíduo como recebido. 38

5.6 Difratograma do RBB após tratamento térmico a $900^{\circ} \mathrm{C}$. $\quad 39$

5.7 Micrografia obtida por MEV, a partir de amostras do RBB, 40 após tratamento térmico a $900^{\circ} \mathrm{C}$.

5.8(a) Micrografia obtida por MEV a partir de amostras de RBB, 40 após tratamento térmico a $900^{\circ} \mathrm{C}$.

5.8(b) Espectro obtido por EDS, a partir da região assinalada. 41

5.9 Triângulo de compatibilidade do diagrama de equilíbrio de 42 fases do sistema $\mathrm{Al}_{2} \mathrm{O}_{3}-\mathrm{CaO}-\mathrm{SiO}_{2}$ localizando a frita a partir dos componentes majoritários.

5.10 Difratograma da frita. 43

5.11 Espectro de FIR da frita. 43

5.12 Análise Térmica Diferencial da frita. 44

5.13 Micrografia a partir da superfície de fragmento da frita, 45 como recebida (imagem obtida por MEV).

5.14 Difratograma de frita tratada a $900^{\circ} \mathrm{C}$ por $0,5-(\mathrm{a}) ; 1,046$ (b) e 2,0 horas (c).

5.15 Triângulos de compatibilidade do diagrama de equilíbrio 
de fases do sistema $\mathrm{Al}_{2} \mathrm{O}_{3}-\mathrm{CaO}-\mathrm{SiO}_{2}$, onde se localizam as composições com F10R (a), F20R e F30R (b), e F40R e F50R(c), respectivamente.

5.16 Difratogramas das composições F1OR (preto), F2OR 52 (vermelho) e F30R (verde), após fusão a $1300^{\circ} \mathrm{C} / 2 \mathrm{~h}$

5.17 Espectros de FTIR das amostras de composições F10R 53 (preto), F20R (vermelho) e F3OR (verde).

5.18 Micrografias das composições com incorporação de 54 resíduo, F10R (a), F20R (b) e F30R (c).

5.17 Difratograma da composição $\mathrm{F} 10 \mathrm{R}$ após tratamento 56 térmico a $900^{\circ} \mathrm{C}$ por 0,5 (preto); 1,0 (vermelho) e $2,0 \mathrm{~h}$ (verde).

5.18 Difratograma da composição F20R após tratamento 56 térmico a $900^{\circ} \mathrm{C}$ por 0,5 (preto); 1,0 (vermelho) e $2,0 \mathrm{~h}$ (verde).

5.19 Difratograma das composições F30R após tratamento 57 térmico a $900^{\circ} \mathrm{C}$ por 0,5 (preto); 1,0 (vermelho) e $2,0 \mathrm{~h}$ (verde).

5.20 Micrografias das amostras F10R-M900 (a), F20R-M900 58 (b) e F30R-M900 (c), devitrificadas por duas horas. 


\section{Índice de Tabelas}

Tabela

Pag.;

3.1 Parâmetros de consumo para obtenção de 1 tonelada de 06 alumina.

3.2 Alguns sistemas formadores de vitrocerâmicos. 16

4.1 Códigos para identificar as fritas com incorporação de 31 Resíduo

4.2 Códigos para identificação das fritas com incorporação 33 de resíduo e tratadas termicamente.

5.1 Distribuição granulométrica por peneiras do Resíduo 34 Borra Branca.

5.2 Composição química do resíduo.-

5.3 Composição química da frita utilizada no trabalho. 41

5.4 Composições calculadas da frita com adição de resíduo. 47

5.5 Comportamento da frita em diferentes temperaturas de 50 fusão e porcentagem de adição de resíduo. 


\section{INTRODUÇÃo}

O passar dos anos fez a humanidade perceber a importância de uma política séria e disposta a conservar o meio ambiente. A partir da industrialização iniciada na Inglaterra, na segunda metade do século XVIII, e dissipada pelo mundo, as indústrias começaram a despejar na natureza variados tipos de rejeitos industriais, muitas vezes, prejudiciais ao ser humano.

Cada empresa tem suas próprias características de processos e produtos, logo, não é possível desenvolver uma política ambiental generalizada para tal; faz-se necessário que cada indústria estude seu processo e desenvolva um sistema de gestão integrado, direcionado ao tipo de resíduo que ela gera; criando assim, um processo paralelo de reaproveitamento de seus próprios rejeitos, e segurança ambiental para a comunidade onde está instalada, diminuindo também os gastos associados ao seu processo produtivo.

Atualmente, existem organismos governamentais de controle, como IBAMA, CONAMA, e demais órgãos estaduais e municipais, criados a partir da verificação da necessidade de se conhecer os tipos de resíduos industriais, e a disposição deles no ambiente.

As alternativas de redução de rejeitos vêm sendo fortemente analisadas dentro de determinadas propostas, cujas principais são: a redução de geração de resíduos na fonte, a reciclagem, o reuso, o tratamento e a disposição final (ROMERO, 2000).

0 rejeito abordado neste trabalho é originado durante 0 processamento para obtenção do alumínio primário. Após a obtenção da alumina $\left(\mathrm{Al}_{2} \mathrm{O}_{3}\right)$, é feita uma reação eletrolítica para separação do íon $\mathrm{Al}^{3+}$, posteriormente transformado em alumínio líquido metálico, processamento este durante o qual forma-se uma escória que contém alta porcentagem de alumínio livre. A extração do alumínio contido nessa escória, também conhecida como borra branca, é 
economicamente interessante, devido o elevado valor agregado do alumínio. No Instituto de Pesquisas Tecnológicas do Estado de São Paulo - IPT vem sendo desenvolvido um processo de extração do alumínio de escórias primárias utilizando-se a tecnologia de plasma térmico.

O plasma é considerado o quarto estado físico da matéria, depois dos três mais conhecidos: sólido, líquido e gasoso. É obtido através da ionização parcial de um gás. Isto é, quando se confere carga positiva ou negativa aos átomos ou moléculas neutras desse gás. $O$ plasma, portanto, é constituído de partículas carregadas, neutras e elétrons. No plasma térmico, que opera em pressões próximas à pressão atmosférica, todas as partículas têm temperaturas semelhantes. Uma vez extraído o alumínio, este método gera um resíduo secundário, o qual denominou-se resíduo borra branca (RBB) que ainda pode oferecer potencial de utilização em produtos industrializados. Neste sentido, e visando contribuir no processo para geração "zero de resíduo" neste processo, este trabalho estuda o aproveitamento total do resíduo gerado pela possibilidade de incorporação deste em fritas vitrocerâmicas.

"Todos têm direito ao meio ambiente ecologicamente equilibrado, bem de uso comum do povo e essencial à sadia qualidade de vida, impondo-se ao Poder Público e à coletividade o dever de defendê-lo e preservá-lo para as presentes e futuras gerações". (Artigo 225 da Constituição Federal de 1988). 


\section{OBJETIVO}

Este trabalho tem por objetivo estudar um processo de utilização do resíduo originado durante a obtenção do alumínio metálico, após remoção do alumínio livre, denominado resíduo borra branca (RBB), verificando a influência da adição do mesmo em fritas vitrocerâmicas.

Oferecer uma opção tecnológica para valorização do resíduo introduzindo-o em um produto cerâmico, além de contribuir definindo procedimentos que levam à geração de resíduo zero. 


\section{REVISÃo DA LITERATURA}

\subsection{A Indústria Mineral no Brasil}

A indústria de exploração mineral, há anos vem fazendo uso de vários métodos de previsão de demanda das suas atividades. Durante os anos 50 e 60 , as previsões eram realizadas utilizando-se apenas projeções, com até certo grau de confiabilidade, devido às baixas taxas de inflação e um crescimento econômico até certo ponto constante. Entretanto, sucessivas mudanças no cenário internacional e a crise de energia de 1973, geraram uma dose crescente de incertezas, nestas previsões (SUSLICK, 1991).

A previsão de consumo de uma substância mineral é um importante elemento de decisão no setor mineralógico, visto que possibilita simular os impactos das substituições, tendências das mudanças tecnológicas e direção dos padrões de consumo mineral.

No Brasil, a produção de alumínio primário alcançou, no primeiro semestre deste ano, 791,3 mil toneladas. Em relação ao mesmo período do ano passado, quando foram produzidas 726,8 mil toneladas, o resultado representou um crescimento de $8,9 \%$ ( $A B A L$, 2006).

\subsection{Bauxita}

A bauxita, que se forma em regiões tropicais e subtropicais por ação do intemperismo sobre aluminossilicatos, é o minério de importância industrial para obtenção do alumínio metálico e de muitos outros compostos.

Os principais constituintes deste material são a gibbsita, $\gamma$ $\mathrm{Al}(\mathrm{OH})_{3}$, e os polimorfos boehmita, $\gamma-\mathrm{AlO}(\mathrm{OH})$, e diaspório, $\alpha-\mathrm{AlO}(\mathrm{OH})$, sendo que as proporções das três formas variam dependendo da localização geográfica do minério. As bauxitas mais ricas em boehmita 
são encontradas em depósitos europeus (França e Grécia) enquanto que aquelas ricas em diaspório, na China, Hungria e Romênia. As bauxitas geologicamente mais novas possuem alto conteúdo de gibbsita, ocorrem em grandes depósitos em áreas de clima tropical como Jamaica, Brasil, Austrália, Guiné, Guiana, Suriname e Índia, e são as que apresentam maior interesse comercial.

A composição típica da bauxita de uso industrial é: $40-60 \%$ de $\mathrm{Al}_{2} \mathrm{O}_{3} ; 12$ - $30 \%$ de $\mathrm{H}_{2} \mathrm{O}$ combinada; 1 - $15 \%$ de $\mathrm{SiO}_{2}$ livre e combinada; $1-30 \%$ de $\mathrm{Fe}_{2} \mathrm{O}_{3} ; 3-4 \%$ de $\mathrm{TiO}_{2} ; 0,05-0,2 \%$ de outros elementos e óxidos (CONSTANTINO, 2002).

As principais reservas de bauxita perfazem um total de 55 a 75 bilhões de toneladas, e são encontradas na América do Sul (33\%), África $(27 \%)$, Ásia $(17 \%)$ e Oceania (13\%), sendo que as três maiores estão localizadas na Guiné $\left(1^{\mathrm{a}}\right)$, Brasil $\left(2^{\mathrm{a}}\right)$ e Austrália ( $\left.3^{\mathrm{a}}\right)$ (USGS, 2006).

\subsection{Processo Bayer}

O processo mais utilizado para transformação da bauxita é o processo Bayer, que é empregado na obtenção de hidróxido e óxido de alumínio. Na FIG. 3.1 apresenta-se um diagrama simplificado do processo.

Além da bauxita e de combustíveis energéticos, a produção de 1 tonelada de alumina requer outros insumos, cujo consumo depende da qualidade do minério extraído. Na TAB. 3.1 apresentam-se os parâmetros de consumo da alumina (ABAL, 2006). 
TABELA 3.1 - Parâmetros de consumo para obtenção de 1 tonelada de alumina.

\begin{tabular}{lc}
\hline \multicolumn{2}{c}{ Parâmetros de consumo - alumina } \\
\hline Bauxita (t/t) & 1,85 a 3,4 \\
\hline Cal $(\mathrm{kg} / \mathrm{t})$ & 10 a 50 \\
\hline Soda cáustica $(\mathrm{kg} / \mathrm{t})$ & 40 a 140 \\
\hline Vapor $(\mathrm{t} / \mathrm{t})$ & 1,5 a 4,0 \\
\hline Óleo combustível - calcinação $(\mathrm{kg} / \mathrm{t})$ & 80 a 130 \\
\hline Floculante sintético $(\mathrm{g} / \mathrm{t})$ & 100 a 1000 \\
\hline Energia elétrica $(\mathrm{kwh} / \mathrm{t})$ & 150 a 400 \\
\hline Produtividade $(\mathrm{Hh} / \mathrm{t})$ & 0,5 a 3,0 \\
\hline Água $\left(\mathrm{m}^{3} / \mathrm{t}\right)$ & 0,5 a 2,0 \\
\hline
\end{tabular}

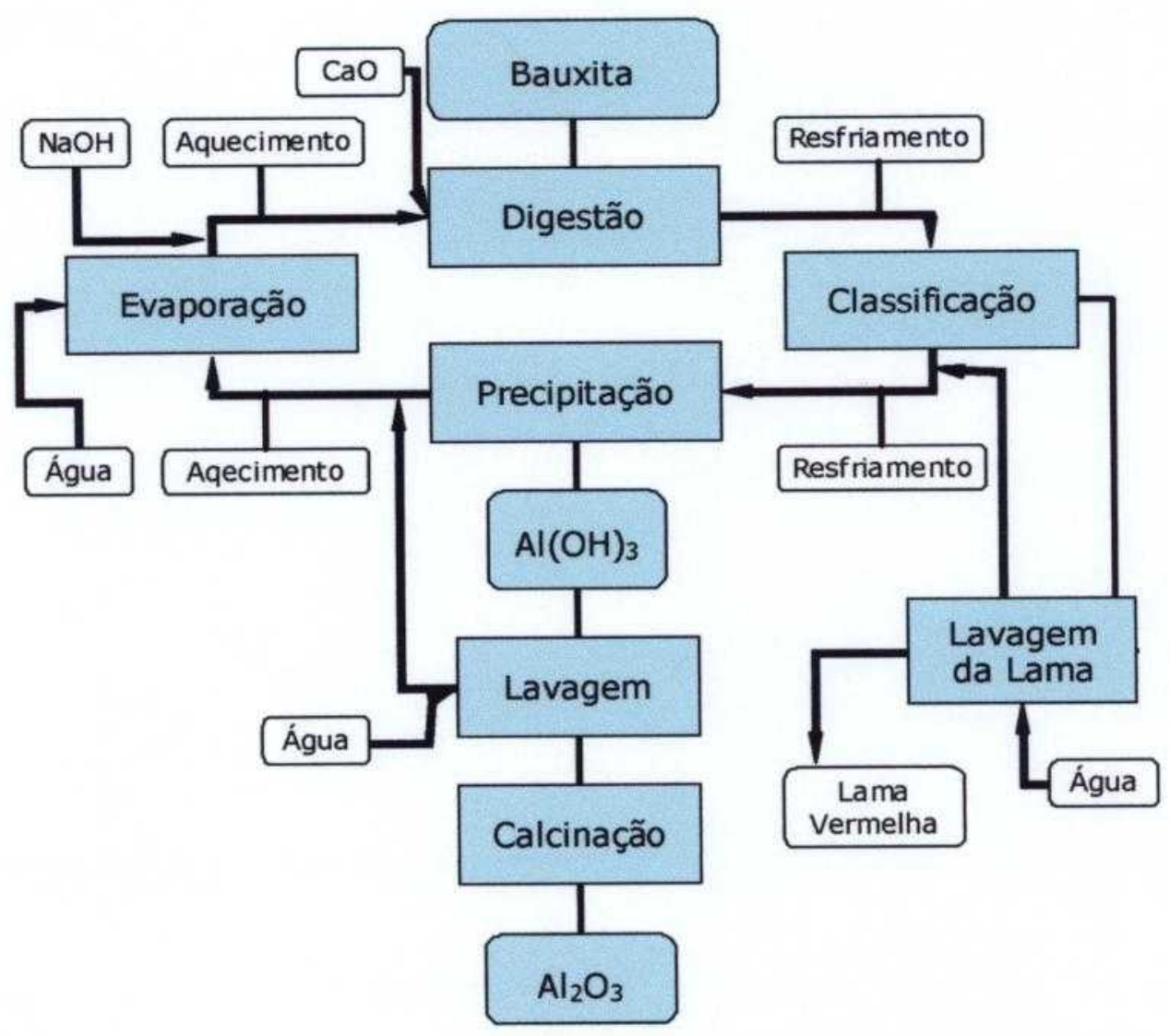

FIGURA 3.1 - Fluxograma simplificado do processo Bayer. 
Mais de $90 \%$ de hidróxido de alumínio produzido no mundo utilizando o processo Bayer é convertido em alumina e usado na indústria do alumínio metálico; esta alumina, obtida pela calcinação do $\mathrm{Al}(\mathrm{OH})_{3}$, é usada no processo eletrolítico Hall-Héroult para a preparação do alumínio metálico (CONSTANTINO, 2002; ABAL, 2006).

Na FIG. 3.2 apresenta-se um esquema simplificado de uma célula de redução de alumínio metálico.

O rendimento deste processo é de cerca de $2: 1$, ou seja, a cada 1 tonelada de alumina são produzidos $500 \mathrm{~kg}$ de alumínio metálico.

O processo de redução para obtenção do alumínio metálico ocorre seguindo as etapas apresentadas a seguir:

- A alumina é dissolvida em um banho em baixa tensão, decompondo-se em oxigênio e alumínio;

- $O$ oxigênio se combina com o ânodo de carbono, desprendendo-se na forma de dióxido de carbono, e o alumínio líquido se precipita no fundo da cuba eletrolítica;

- O metal líquido (já alumínio primário) é transferido para a re-fusão através de cadinhos;

- São produzidos os lingotes, placas e tarugos de alumínio primário. 


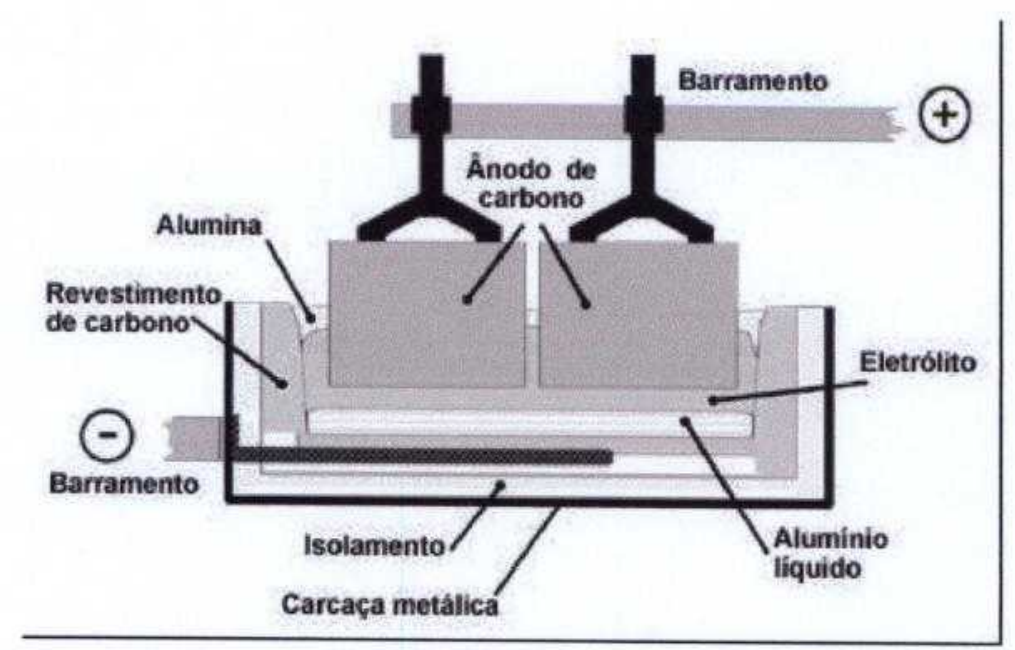

FIGURA 3.2 - Esquema simplificado de uma célula de redução de alumínio metálico.

\subsection{Alumínio}

O uso deste elemento em materiais cresce continuamente com o passar dos anos, como resultado de um aumento no entendimento de sua química e da viabilidade de uma ampla faixa de compostos contendo alumínio.

O alumínio é o terceiro elemento mais abundante na crosta terrestre, sendo o primeiro entre os metais e, só excedido pelo oxigênio e silício ( $\mathrm{O}=45,5 \% ; \mathrm{Si}=25,7 \% ; \mathrm{Al}=8,3 \% ; \mathrm{Fe}=6,2 \% ; \mathrm{Ca}=4,6 \%$; outros = 9,7\% em massa) (ATWOOD, 2000; CONSTANTNO, 2002).

A combinação desta abundância com suas propriedades mecânicas e elétricas únicas torna-o amplamente utilizado em aplicações industriais, como equipamentos elétricos, transportes, construção civil, petroquímica, metalúrgica e outras; e também em aplicações cotidianas, como em móveis, eletrodomésticos, brinquedos, utensílios de cozinha, embalagens, latas, produtos de higiene, farmacêutico e cosméticos. Embora a sua forma mais conhecida seja a metálica, é encontrado na natureza em combinação com outros elementos, como o oxigênio com o qual apresenta uma forte ligação e em forma de silicatos. 
Os compostos de íons $\mathrm{Al}^{3+}$ que apresentam maior relevância industrial no mundo atual são $\mathrm{Al}(\mathrm{OH})_{3}, \mathrm{Al}_{2} \mathrm{O}_{3}, \mathrm{Na}\left[\mathrm{Al}(\mathrm{OH})_{4}\right], \mathrm{Al}_{2}\left(\mathrm{SO}_{4}\right)_{3} \mathrm{e}$ haletos de alumínio, dos quais os dois primeiros, utilizados para produção do metal, são os de maior importância econômica (CONSTANTINO, 2002).

O metal, originalmente nomeado alumínio por Davy em 1807, não foi isolado, nem teve a sua forma definida até meados de 1820 quando Oested e Wohler reduziram o óxido a alumínio metálico (ATWOOD, 2000; MÁRTIRES, 2001). Os compostos de alumínio, por outro lado, servem à humanidade há mais de 4000 anos (CONSTANTINO, 2002).

Apenas nos dois primeiros meses deste ano o Brasil produziu 253,9 mil toneladas de alumínio primário, registrando um aumento de $7,6 \%$ em relação ao mesmo período do ano passado (ABAL, 2006).

\subsection{Resíduos no Brasil}

Os estudos ambientais estiveram por um longo período restritos ao meio científico, presentes na linguagem das ciências naturais e da Terra. Na última década, no entanto, estes problemas começaram a ganhar visibilidade dos organismos de controle, despertando a atenção em todos os ramos da sociedade, em particular os produtivos, da agricultura à indústria.

Para a comunidade científica, este fato tem implicado em uma re-configuração no modo de encarar essas questões, requerendo uma atenção maior devido às complexidades tanto sob o ponto de vista legislativo como em soluções técnicas específicas e em caráter definitivo.

No Brasil, apesar da tendência à descentralização das instalações industriais, observada atualmente com o aumento dos benefícios oferecidos pelos estados do Nordeste, as Regiões Sul e Sudeste ainda possuem os estados mais industrializados. 
As mudanças ainda são lentas na diminuição do potencial poluidor do parque industrial brasileiro, principalmente no tocante às indústrias mais antigas, que continuam contribuindo com a maior parcela da carga poluidora gerada e elevado risco de acidentes ambientais. Deste modo ainda é necessário altos investimentos de controle ambiental e custos de despoluição para monitorar a emissão de poluentes, lançamento de efluentes e depósito irregular de resíduos perigosos. As indústrias tradicionalmente responsáveis pela maior produção de resíduos perigosos são as metalúrgicas, as indústrias de equipamentos eletro-eletrônicos, as fundições, a indústria química e a indústria de couro e borracha (MMA, 2006).

Nas áreas urbanas, a disposição final de resíduos é inadequada. Por exemplo, o lançamento dos resíduos industriais perigosos em lixões, nas margens das estradas ou em terrenos baldios, que compromete a qualidade ambiental e de vida da população.

Na Região Metropolitana de São Paulo, estima-se que atualmente há cerca de 116 lixões de depósito doméstico e industrial sem qualquer controle, e cerca de 2.300 áreas potencialmente contaminadas em função de atividades industriais. Do total de 2,5 milhões de toneladas de resíduos industriais gerados por ano, $188 \mathrm{mil}$ toneladas são consideradas perigosas (Classe I, ABNT - 2004), dos quais cerca de $44 \%$ são depositados de forma inadequada, e os restantes são estocados ou recebem algum tratamento (MMA, 2006).

0 tratamento mais comum é a incineração. Cerca de 20 mil toneladas são queimadas anualmente em uma das 13 usinas existentes. A maior parte dos resíduos industriais, no entanto, são resíduos de Classe II, ABNT - 2004. Destes $56 \%$ são tratados ou estocados. A outra parte é depositada em aterros e depósitos de lixo (lixões), sendo que 866 mil toneladas por ano (84\%) são depositadas em locais inadequados. As principais formas de destinação de resíduos sólidos industriais continuam sendo o depósito nos "lixões" municipais (14\%) e "lixões" particulares (20\%). Os resíduos ainda são estocados em lagoas 
(12\%), vendidos a terceiros $(17 \%)$, ou são processados ou reciclados externamente (17\%) (MMA, 2006).

Para tratar a questão dos resíduos industriais, o Brasil possui legislações e normas específicas. Pode-se citar a Constituição Brasileira em seu Artigo 225, que dispõe sobre a proteção ao meio ambiente; a Lei 6.938/81, que estabelece a Política Nacional de Meio Ambiente; a Lei $6.803 / 80$, que dispõe sobre as diretrizes básicas para o zoneamento industrial em áreas críticas de poluição.

As resoluções do CONAMA 257/263 e 258 dispõem respectivamente sobre pilhas, baterias e pneumáticos, sendo esta questão ainda amplamente tratada nos Capítulos 19, 20 e 21 da Agenda 21 (Rio-92).

Em síntese, o Governo Federal, por meio do Ministério do Meio Ambiente (MMA) e Instituto Brasileiro do Meio Ambiente e dos Recursos Naturais Renováveis (IBAMA), está desenvolvendo projeto para caracterizar os resíduos industriais através de um inventário nacional, para traçar e desenvolver uma política de atuação, visando reduzir a produção e destinação inadequada de resíduos perigosos (MMA, 2006).

\subsection{Resíduos Sólidos Industriais}

Podemos considerar resíduos sólidos industriais, os resíduos que se apresentam num estado sólido ou semi-sólido, incluindo lodos e até mesmo determinados líquidos, cujas características, tornem inviáveis o seu descarte em redes públicas de esgoto ou na natureza; ou ainda, que exijam, para isso, soluções economicamente inviáveis.

A partir do momento em que se percebeu a crescente evolução no número de empresas e, conseqüentemente, da quantidade de detritos gerados, os organismos de normalização e controle viram-se obrigados a formular uma classificação para os resíduos industriais.

A ABNT (Associação Brasileira de Normas Técnicas) editou um conjunto de normas para padronizar os resíduos sólidos industriais, classificando-os em duas classes (ABNT, 2004): 
- Classe I - resíduos perigosos - em função de suas características de inflamabilidade, corrosividade, reatividade, toxicidade e patogenicidade, podem apresentar riscos à saúde pública ou efeitos adversos ao meio ambiente;

- Classe II A - resíduos não inertes;

- Classe II B - resíduos inertes: não sofrem transformações físicas, químicas ou biológicas significativas a ponto de acarretar risco à saúde e ao meio ambiente (restos de construção, vidros, certos plásticos e borrachas de difícil decomposição);

A classificação dos resíduos envolve a identificação do processo ou atividade que lhes deu origem, de seus constituintes e características e a comparação destes constituintes com listagens de resíduos e substâncias cujo impacto à saúde e ao meio ambiente é conhecido (FLOHR, 2005).

A norma NBR 10004 (Resíduos Sólidos) classifica os resíduos; a NBR 10005 trata da Lixiviação; a NBR 10006 trata da Solubilização e a NBR 10007 trata da Amostragem de resíduos.

A aplicação dessas normas nos procedimentos industriais contribui para que ocorra um desenvolvimento sustentável, procurando utilizar "tecnologias limpas", evitando ao máximo o descarte de algum tipo de insumo; o que por conseqüência reduz a geração de resíduos.

A indústria produtora de alumínio é grande geradora de resíduo. Para que seja produzida 1 tonelada de alumínio primário, é necessário aproximadamente $1920 \mathrm{~kg}$ de alumina, que na produção de $1000 \mathrm{~kg}$ consome de 1,85 a 3,4 toneladas de bauxita, dependendo da "pureza" do mineral.

O Instituto de Pesquisas Tecnológicas do Estado de São Paulo (IPT), desenvolve o processo de recuperação do alumínio contido no 
resíduo gerado em algumas empresas produtoras de alumínio primário, processo este que utiliza o plasma térmico.

\subsection{Plasma Térmico}

O plasma térmico pode ser entendido como sendo um gás parcialmente ionizado a altas temperaturas, conferindo-se cargas positivas e / ou negativas aos átomos ou moléculas neutras desse gás.

Como o plasma tem partículas carregadas, ele atua como um condutor de eletricidade. Essa característica possibilita seu uso como uma resistência elétrica comum. Quando se fornece energia elétrica ao sistema, o plasma faz a conversão para energia térmica, de forma bastante eficiente. Geradores de plasma térmico usados industrialmente podem atingir temperaturas que variam de 3.500 a $20.000^{\circ} \mathrm{C}$.

De um modo geral, qualquer gás pode ser utilizado para a geração do plasma. No processo de obtenção do alumínio metálico, utilizado pelo IPT, como a presença de oxigênio é indesejável, pois reage muito facilmente com o alumínio, é utilizado argônio, um gás inerte que não reage com qualquer outra substância, em baixa vazão, mas o suficiente para controle da atmosfera do processo.

Sem oxigênio na atmosfera do forno, a oxidação do alumínio é evitada, dispensando também uso dos sais fundentes, que são considerados como os maiores agentes poluidores do processo. Além disso, a eficiência térmica do processo é bem elevada, se comparada àqueles que envolvem combustão, uma vez que o sistema envolve muito baixa vazão de gás e, ao contrário do que ocorre no processo convencional, muito pouca energia perde-se na forma de entalpia dos gases quentes de exaustão. $O$ resíduo gerado, sem os sais adicionados ao processo convencional, pode ser reciclado. 


\subsection{Materiais Vitrocerâmicos}

A formação de um vitrocerâmico é extremamente complexa e geralmente, segue uma seqüência de quatro passos (KIRK and OTHMER, 1994):

- Uma fase amorfa dispersa, estruturalmente incompatível com a matriz vítrea, geralmente instável e enriquecida com um ou dois óxidos chaves, por exemplo, $\mathrm{TiO}_{2}$ ou $\mathrm{ZrO}_{2}$ formadas no resfriamento ou re-aquecimento do vidro.

- Núcleos cristalinos primários, formados tanto heterogeneamente nos limites das fases como homogeneamente dentro da segunda fase.

- Uma fase cristalina metaestável, heterogeneamente nucleada, sobre os cristalitos primários e crescidos, geralmente à custa de uma segunda fase vítrea. Este fato produz um material de solução sólida tipicamente metaestável e finamente granulada.

- O material metaestável tende a se estabilizar por meio da formação de estruturas cristalinas finas, transformações de fases alotrópicas, reações entre fases metaestáveis, ou precipitação.

Os vitrocerâmicos são sólidos policristalinos contendo fase vítrea residual. Ainda que não haja um consenso na concentração de fase cristalina, se consideram os materiais que apresentam mais de $50 \%$ de cristalinidade, podendo alcançar 90\% (KIRK e OTHMER, 1994).

0 processo mais utilizado para a sua obtenção é a partir fusão do vidro, conformação em produtos, e posterior tratamento térmico, conduzindo à cristalização controlada. Esta cristalização que se dá submetendo-se vidros de composições adequadas a um cuidadoso tratamento térmico resulta no controle tanto da nucleação como no crescimento de fases dentro do vidro. Em muitos casos o processo de 
cristalização pode ser quase completo, contudo uma pequena proporção de fase residual vítrea estará sempre presente. Essa fase residual exerce grande influência sobre importantes propriedades nos materiais vitrocerâmicos.

Algumas vezes chamados de vidro recristalizado, a nucleação da fase cristalina pode ocorrer na interface energeticamente favorável entre as fases líquidas, então, a interface líquido-líquido detém um efeito significativo na etapa de nucleação do processo de cristalização dentro de um vidro (PAUL, 1982; PANNHORST, 1997).

As propriedades finais desse material podem ser previstas em função das proporções entre as fases cristalinas e vítreas. E por sua vez, estas propriedades irão definir suas possibilidades de uso.

Materiais vitrocerâmicos podem ser produzidos a partir de uma grande variedade de tipos de vidro; alguns dos mais importantes estão relacionados na TAB. 3.2, que apresenta uma relação de materiais vitrocerâmicos e principais fases presentes (PAUL, 1982).

TABELA 3.2 - Alguns sistemas formadores de vitrocerâmicos.

\begin{tabular}{|c|c|c|}
\hline SISTEMA & Agentes Nucleantes & Fases Cristalinas \\
\hline $\begin{array}{l}\mathrm{Li}_{2} \mathrm{O}-\mathrm{Al}_{2} \mathrm{O}_{3}-\mathrm{SiO}_{2} \\
\left(\mathrm{Al}_{2} \mathrm{O}_{3}>10 \%\right)\end{array}$ & $\begin{array}{l}\mathrm{TiO}_{2} ; \mathrm{TiO}_{2}+\mathrm{P}_{2} \mathrm{O}_{5}+ \\
\mathrm{ZrO}_{2}\end{array}$ & $\begin{array}{l}\beta \text {-espodumênio } / \\
\text { eucriptita } \\
\text { Soluções sólidas }\end{array}$ \\
\hline $\begin{array}{l}\mathrm{Li}_{2} \mathrm{O}-\mathrm{Al}_{2} \mathrm{O}_{3}-\mathrm{SiO}_{2} \\
\left(\mathrm{Al}_{2} \mathrm{O}_{3}<10 \%\right)\end{array}$ & $\mathrm{P}_{2} \mathrm{O}_{5}$ & $\begin{array}{l}\text { Dissilicato de lítio, } \\
\text { quartzo }\end{array}$ \\
\hline $\begin{array}{l}\mathrm{Li}_{2} \mathrm{O}-\mathrm{ZnO}-\mathrm{PbO}- \\
\mathrm{SiO}_{2}\end{array}$ & $\mathrm{P}_{2} \mathrm{O}_{5}$ & $\begin{array}{l}\text { Dissilicato de lítio, } \\
\text { silicato de zinco e lítio, } \\
\text { quartzo }\end{array}$ \\
\hline $\mathrm{MgO}-\mathrm{Al}_{2} \mathrm{O}_{3}-\mathrm{SiO}_{2}$ & $\mathrm{TiO}_{2}$ & Cordierita, cristobalita \\
\hline $\begin{array}{l}\mathrm{Na}_{2} \mathrm{O}-\mathrm{BaO}-\mathrm{Al}_{2} \mathrm{O}_{3}- \\
\mathrm{SiO}_{2}\end{array}$ & $\mathrm{TiO}_{2}$ & Nefelina, hexacélsio \\
\hline $\mathrm{ZnO}-\mathrm{Al}_{2} \mathrm{O}_{3}-\mathrm{SiO}_{2}$ & $\mathrm{P}_{2} \mathrm{O}_{5}, \mathrm{TiO}_{2}$ & Vilemita \\
\hline
\end{tabular}


Uma primeira necessidade para que um material vitrocerâmico se torne comercial é que possa ser fundido e facilmente obtido utilizando-se fornos refratários usuais.

Vitrocerâmicos podem ser, por exemplo, produzidos tendo um coeficiente de expansão térmica variando de valores negativos a altos valores positivos próximos aos dos metais como aço e cobre (PANNHORST, 1997).

Compostos de uma maneira geral, contendo grande quantidade de alumina, necessitam de altas temperaturas, devido à sua refratariedade.

O vidro formado deve ser suficientemente estável para que não se devitrifique durante a operação de formação; caso isto aconteça pode haver aparecimento de cristais maiores ocasionando perda de resistência.(RAWLINGS, 2004).

Os vitrocerâmicos têm uma variedade de aplicações, como: substratos microeletrônicos, componentes óticos transparentes, implantes biomédicos, suportes catalíticos, membranas e sensores, bem como matrizes para materiais compostos.

Entre as suas várias propriedades, destaca-se sua elevada resistência mecânica, atribuída aos seguintes fatores (NAVARRO, 1991; PAUL, 1982):

- Não apresentam porosidade como a encontrada nas cerâmicas convencionais;

- Materiais vitrocerâmicos são mais resistentes à abrasão que vidros normais, logo são menos susceptíveis a danos superficiais que causam defeitos;

- Nos vidros, a trinca se propaga por uma fase simples homogênea, nos vitrocerâmicos a trinca tem que atravessar fronteiras que são os limites das fases. A trinca pode caminhar pelas fronteiras dos grãos; o pequeno tamanho de 
grão nos vitrocerâmicos exerce um importante papel nas suas propriedades mecânicas.

Estas características inerentes dos vitrocerâmicos os fazem particularmente atraentes para aplicações onde dureza e resistência a um ambiente agressivo são importantes.

\subsection{Histórico}

Vários autores estudam vêem estudando a utilização de resíduos como constituintes de outros materiais cerâmicos, e a aplicação em vidros é uma prática muito difundida entre os pesquisadores. Não existe um processo de manufatura com geração zero de resíduo, portanto a reciclagem e o reuso de resíduos são necessários.

Vários estudos são constantemente realizados visando incorporar resíduos em materiais vitrocerâmicos, para isto, são utilizados diferentes meios de incorporação, vários sistemas formadores de vidros são estudados e diferentes técnicas de análises são empregadas para caracterização dos materiais obtidos.

0 sistema $\mathrm{Al}_{2} \mathrm{O}_{3}-\mathrm{CaO}-\mathrm{SiO}_{2}$ (ACS) é um dos mais utilizados como base para obtenção de vitrocerâmicas. CHENG, T. W. et al., em 2002, que obteve vitrocerâmico a partir da utilização de cinzas de um incinerador de resíduo sólido municipal pela tecnologia de sinterização de pó. Esse processo foi usado para transformar o resíduo incorporado ao sistema ACS em material vitrocerâmico. A principal fase encontrada foi a Guelenita $\left(\mathrm{Ca}_{2} \mathrm{Al}_{2} \mathrm{SiO}_{7}\right)$, que apresentou boas propriedades físicas e mecânicas.

TANAKA, M., 2004, obteve vitrocerâmicas baseado no sistema ACS utilizando em suas composições resíduos inorgânicos. As principais fases cristalinas encontradas após os tratamentos de nucleação foram a Volastonita e Anortita, precipitadas homogeneamente no material; ocorrendo também precipitação de Nefelina e Guelenita. 
O autor DUAN, R. G. et al., 1998-C, estudou a cristalização de vidros no mesmo sistema, o ACS, a partir de matérias-primas puras, onde fez interessantes observações quanto à morfologia e crescimento das fases cristalinas nos vitroceramicos resultantes. Entre estas observações destaca o autor que, após os tratamentos térmicos de cristalização, realizados em temperaturas ligeiramente superiores à temperatura de transição vítrea, apenas observou-se a ocorrência de separação de fases ambas amorfas. Entretanto, quando o mesmo material foi tratado, em temperaturas próximas à temperatura de cristalização, apresentou uma estrutura de cristais finos no interior da amostra e grandes dendritas formadas a partir na superfície, com a direção de crescimento voltada para o interior do material. Também verificou que este crecimento acentua-se com o aumento do tempo de tratamento. Quando o tratamento térmico de cristalização foi realizado na temperatura na temperatura de cristalização, observou a presença destes cristais também na superfície da amostra, com a mesma característica de direção de crescimento voltado o interior. Ainda assim estes cristais paresentaram dimensões submicronicas indicando que a sua nucleaçao se deu lentamente. Este mesmo material, tratado novamente em temperatura pouco acima da temperatura de cristalização por um longo tempo não apresentou cristalização superficial, e no interior a amostra apresentou-se novamente com separação de fases e os minúsculos cristais se dissolvem.

ROSKOSZ, M. et al., 2005, também estudou a nucleação e crescimento de grãos a uma temperatura de aproximadamente $100^{\circ} \mathrm{C}$ acima da temperatura de transição vítrea a partir de 12 composições distintas de líquidos pertencentes ao sistema ACS. Observou o pesquisador que a nucleação ocorre na interface gás-líquido originando várias estruturas cristalinas, "Yoshiokaite", Guelenita, Larnita, Anortita e Volastonita. As análises de Raman e Microscopia Eletrônica de Transmissão (MET) efetuadas indicaram que as fases são altamente 
desordenadas, pouco cristalizadas, e, geralmente não são estequiométricas.

Em outro trabalho, DUAN, R. G. et al., 1998-B, estudou a influência da alteração da quantidade de $\mathrm{TiO}_{2}$ em um vidro do sistema ACS e a formação de fase cristalina com tratamento térmico. A energia de ativação para crescimento do cristal foi analisada pela técnica de ATD e o grau de cristalização foi analisado por MEV. A cristalização foi observada em todas as amostras do sistema estudado, e cristais dendríticos foram encontrados. $O$ autor constatou que: com o aumento de $\mathrm{TiO}_{2}$, a temperatura de transição vítrea diminui e, conseqüentemente, a temperatura de cristalização também diminui; a adição de $8-10 \%$ de $\mathrm{TiO}_{2}$ (em massa) foi a mais efetiva; e que a diferença do módulo de elasticidade do vidro base e do vidro modificado com adição do $\mathrm{TiO}_{2}$ foi pequena. Os resultados experimentais mostraram também que a adição de $\mathrm{TiO}_{2}$ não promove por si só uma cristalização efetiva.

Diversos pesquisadores estudaram a utilização de resíduos sólidos municipais provenientes de incineradores de resíduos como constituintes para obtenção de materiais vitrocerâmicos. BOCCACCINI, A. R. et al., 1995, obteveram vitrocerâmica do sistema ACS utilizando este tipo de resíduo sem a adição de aditivos nucleantes. $O$ tratamento térmico de nucleação e cristalização foi dividido em duas etapas, $880^{\circ} \mathrm{C}$ por $1 \mathrm{~h}$ e $950^{\circ} \mathrm{C}$ por $10 \mathrm{~h}$. Os vitrocerâmicos obtidos apresentaram melhores propriedades mecânicas e termomecânicas que os vidros de origem, tornando-se potenciais candidatos à aplicações industriais.

A pesquisadora BARBIERI, L. et al., 1999, também obteve vidros e vitrocerâmicos pela mistura de até $50 \%$ de resíduo sólido de incineradores municipais da Itália e Espanha com outros resíduos. Foram preparadas 10 composições que foram analisadas pelas técnicas de ATD, DRX e MEV, além de análises químicas e mecânicas. Nesse trabalho a autora verificou que a presença de metais alcalinos na 
composição fundamental facilita a obtenção dos vitrocerâmicos com uma microestrutura fina, melhorando as propriedades mecânicas.

Em outro trabalho BARBIERI, L. et al., 2000, estudou a sinterização e cristalização de pós de vidro obtidos a partir de resíduos de silicato vitrificados; os resíduos utilizados foram cinzas de um incinerador de resíduos sólidos municipais e resíduo de feldspato, que foram misturados em diferentes proporções mantendo-se a porcentagem de $\mathrm{SiO}_{2}$ em mais de $46 \%$. A autora observou que o estágio de sinterização iniciou a $750^{\circ} \mathrm{C}$ para todas as proporções analisadas e finalizou 100 a $150^{\circ} \mathrm{C}$ depois, dependendo da composição. A cristalização ocorreu no último estágio da sinterização. Os produtos obtidos foram analisados pelas técnicas de ATD, DRX e MEV, e a autora concluiu que é possível obter vitrocerâmica a partir de pós com tamanho médio de partículas menor que $45 \mu \mathrm{m}$; o grau de cristalização e o tipo de fase cristalina formada não são afetados pelo tamanho de partícula inicial dos pós utilizados.

KARAMANOV, A. et al., 2003, utilizando apenas resíduos sólidos, $70 \%$ de cinzas de incinerador municipal e 30\% de resíduo de feldspato obteve um material vitrocerâmico e estudou a influência da taxa de aquecimento na cristalização. A estabilidade química do vidro foi analisada por ensaio de lixiviação e a análise térmica por ATD foi utilizada, demonstrando que o vidro apresentava uma tendência à cristalização a $935^{\circ} \mathrm{C}$, da fase Guelenita. A porcentagem de fase cristalina formada é função do tratamento térmico, que foi analisado pela variação da densidade e DRX. Para obtenção dos produtos vitrocerâmicos, a frita foi tratada termicamente em cadinhos de alumina a 950,1000 e $1050^{\circ} \mathrm{C}$, com taxas de aquecimento de 2 e $20^{\circ} \mathrm{C} / \mathrm{min}$. Com a maior taxa de aquecimento, a cristalização ocorre em forma de fibras nucleadas e crescidas perpendicularmente a partir da superfície; a menor taxa de aquecimento para cristalização impede a sinterização da amostra. 
Utilizando um resíduo típico da indústria de obtenção do alumínio metálico, a lama vermelha, originada na extração e lavagem da bauxita, PENG, F. et al., 2005, obteve vidros pela fusão deste resíduo com adição de aditivos. Tratamentos térmicos foram utilizados para obtenção de nano cristais vitrocerâmicos; a nucleação desses cristais foi iniciada pela presença de impurezas presentes no resíduo, que serviram de agentes nucleantes onde a principal fase cristalina verificada nas amostras foi a Volastonita $\left(\mathrm{CaSiO}_{3}\right)$. Esses cristais forsm encontrados homogeneamente dispersos no vidro de origem, com um tamanho médio de menos de $100 \mathrm{~nm}$. O tamanho médio dos cristais varia de acordo com o tratamento térmico utilizado. $O$ autor examinou as propriedades mecânicas e físicas, como densidade, coeficiente de expansão térmica, dureza e resistência mecânica. Em cada amostra a microestrutura correspondente foi analisada, levando o autor a concluir que as amostras apresentam boas propriedades mecânicas devido à às características microestruturais observadas.

Considerando os resultados encontrados na literatura e aqui descritos, este trabalho faz um estudo da influência do resíduo sólido resultante dos processos de extração de alumínio metálico a partir dos óxido e hidróxidos na formação de fritas vitrocerâmicas utilizadas na fabricação de esmaltes vitrocerâmicos. 


\section{MATERIAIS E MÉtODOS}

\subsection{Matérias-primas}

Os materiais utilizados para este estudo foram: o resíduo borra branca, aqui denominado "RBB", e uma frita mate comercial, denominada pela letra " $F$ ".

\subsubsection{Resíduo}

O Resíduo utilizado neste trabalho é resultante do processo de recuperação de alumínio residual pela técnica de forno a plasma. A amostra, fornecida pelo Departamento de Mecânica e Eletricidade Laboratório de Plasma Térmico - Instituto de Pesquisas Tecnológicas de São Paulo (IPT), foi coletada utilizando-se procedimentos de amostragem, acompanhada de homogeneização para garantir a confiabilidade e representatividade dos resultados.

\subsubsection{Fritas}

A frita utilizada neste estudo é um produto comercial, produzido pela Ferro Enamel do Brasil.

De posse dos materiais de partida, deu-se início às caracterizações pelas técnicas de análises adequadas, e ao estudo de incorporação do resíduo à frita.

\subsection{Técnicas de Análise}

As matérias-primas $e$ as composições obtidas foram caracterizadas utilizando as técnicas apresentadas a seguir:

\subsubsection{Espectrometria por Fluorescência de Raios X - FRX}

A determinação da composição química foi realizada por análise de espectrometria por fluorescência de raios-X, FRX. Neste 
trabalho foi utilizado o método semi-quantitativo de parâmetros fundamentais.

O equipamento utilizado foi o Espectrômetro de Fluorescência de Raios X, marca Rigaku, modelo X-Ray Rix2000.

As amostras utilizadas para análise foram enviadas na forma

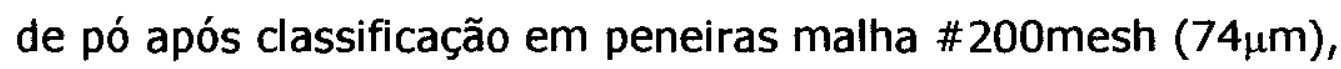

\subsubsection{Espectrometria por Difração de Raios X - DRX}

Esta técnica foi utilizada para identificar as possíveis fases cristalinas presentes no resíduo e nas amostras estudadas. Os parâmetros de análise utilizados para o resíduo foram: ângulo $2 \theta$ de 10 a $80^{\circ} \mathrm{com}$ velocidade de $2 \% / \mathrm{min}$.

O equipamento utilizado foi o Difratômetro de Raios X Rigaku, modelo Multiflex, tubo de cobre, radiação $\mathrm{k}$ alfa com monocromador, comprimento de onda do $\mathrm{Cu},(\lambda=1,5406 \AA)$.

As amostras utilizadas para análise foram enviadas na forma de pó classificados em peneiras malha \#100mesh (<150 $\mu \mathrm{m}$ ).

\subsubsection{Análise Térmica Diferencial e Termogravimétrica - ATD / ATG}

A análise térmica diferencial consiste na medida da diferença de temperatura que pode existir entre uma amostra e um material de referência inerte; enquanto ambos os materiais, simultaneamente, sofrem um aquecimento ou resfriamento controlado. A medida da diferença de temperatura é realizada com a ajuda de termopares colocados em contato com os suportes onde se encontram os materiais e outro termopar, que registra a medida da temperatura do sistema (forno).

Por este método é possivel detectar uma multiplicidade de transformações que implicam em reações energéticas, que podem ser devido a fenômenos físicos ou químicos resutado de reações endotérmicas (absorção de calor) ou exotérmicas (liberação de calor). A 
interpretação desta curva de ATD é muito delicada e na maior parte dos casos, difícil. Por isso, outros tipos de análises são necessárias para complementá-la.

Devidso as transformações de ordem estrutural que também resultam em absorção ou liberação de energia, é possível para os materiais vítreos determinar nestas análises as temperaturas ou intervalo de temperatura onde ocorre a transição vítrea, temperatura de início de cristalização, e as temperaturas onde o material começa a se fundir. Todas as características mencionadas acima são influenciadas por diversos fatores, tais como equipamento de medida, natureza e preparação das amostras, velocidade de aquecimento e, atmosfera que circunda a amostra. Todos estes parâmetros devem ser controlados para se obetr um resultado confiável (DUNN, 2002).

Para o resíduo, a análise foi realizada com uma velocidade de aquecimento de $5^{\circ} \mathrm{C} / \mathrm{min}$, até a temperatura de $1300^{\circ} \mathrm{C}$, seguido de resfriamento e fluxo de ar normal sintético. Para as fritas a velocidade de aquecimento foi de $12,5^{\circ} \mathrm{C} / \mathrm{min}$ até a temperatura $900^{\circ} \mathrm{C}$ e resfriamento análogo ao resíduo.

O equipamento utilizado para esta análise foi o SDT-2960 da TA Instrumentos.

\subsubsection{Diâmetro médio equivalente (distribuição granulométrica por dispersão a laser) - CILAS}

Esta técnica consiste em medir o tamanho de partículas utilizando os fenômenos de difração e a interferência de um feixe de laser ao atravessar 0 meio onde se encontram as partículas em suspensão.

O analisador de partículas a laser (CILAS), marca CILAS Granulometer 1064, foi utilizado para determinar a distribuição dos tamanhos de partículas do resíduo.

\subsection{5 Área de Superfície Específica - BET}


Esta técnica utiliza os princípios estabelecidos por Brunauer, Emmett e Teller (BET) em 1938 para calcular a área de superfície específica da amostra utilizando a quantidade de gás nitrogênio adsorvido pela amostra para cálculo da área (RICCI, 1984).

$O$ equipamento utilizado para cálculo da área de superfície específica foi o Micromeritics modelo ASAP 2000. As medidas foram realizadas em cinco ciclos, e as amostras enviadas foram previamente classificadas em malha \#200mesh $(<74 \mu \mathrm{m})$.

\subsubsection{Massa Específica Real - Picnometria de Gás Hélio}

Esta técnica foi utilizada para determinar da densidade específica real do resíduo. A técnica utiliza a adsorção de gás hélio para cálculo da massa específica. A análise foi realizada em amostras extrídas do materila após classificação em malha \#200mesh $(74 \mu \mathrm{m})$. 0 equipamento utilizado análise foi o Micromeritics, modelo 1330.

\subsubsection{Análise morfológica - Microscopia Eletrônica de Varredura - MEV / EDS}

A técnica de MEV foi utilizada para observar a morfologia e distribuição do tamanho de partículas das amostras de resíduo como recebido (RR) e após calcinação a $900^{\circ} \mathrm{C}$ por 2 horas (RC); as amostras da frita pura, fritas com resíduo incorporado e, posteriormente, as fritas com resíduo incorporado e tratadas termicamente também foram analisadas quanto à morfologia, nucleação e fases cristalinas encontradas.

As análises de MEV foram realizadas no equipamento da Philips modelo XL-30, utilizando energia de $20 \mathrm{kv}$, as amostras analisadas na forma de pó malha após calssificação em \#100mesh (< $150 \mu \mathrm{m})$. O pó foi impregnado no porta-amostra e recoberto com ouro.

A análise espectrográfica de energia dispersiva (EDS) foi utilizada para identificar a composição pontual dos elementos presentes 
nas amostras analisadas do material observado no MEV. Esta análise foi realizada no resíduo após calcinação.

\subsubsection{Análise por Espectrometria de Infravermelho - FTIR}

Esta técnica foi aplicada para verificação da efetividade da incorporação do resíduo na frita cerâmica identificando os agrupamentos funcionais que compõem a estrutura.

As amostras foram preparadas em matrizes de $\mathrm{KBr}$ de grau espectrofotométrico (Merck P.A.) e conformadas em pastilhas. Como para determinados comprimentos de onda a capacidade de penetração da radiação infravermelho é baixa, as amostras enviadas para análise foram classificadas em peneira malha 100 mesh, abaixo de $150 \mu \mathrm{m}$, a fim de amenizar o efeito de variação na composição superficial (SIGOLI, 2001; MACDONALD, 2000; FUJTTA, 2003).

0 equipamento utilizado para realização do ensaio foi da marca Thermo Nicolet modelo Nexus 870 FT-IR. 


\subsection{Procedimento Experimental}

O desenvolvimento do trabalho experimental e suas etapas são apresentadas no diagrama de blocos da FIG. 4.1.

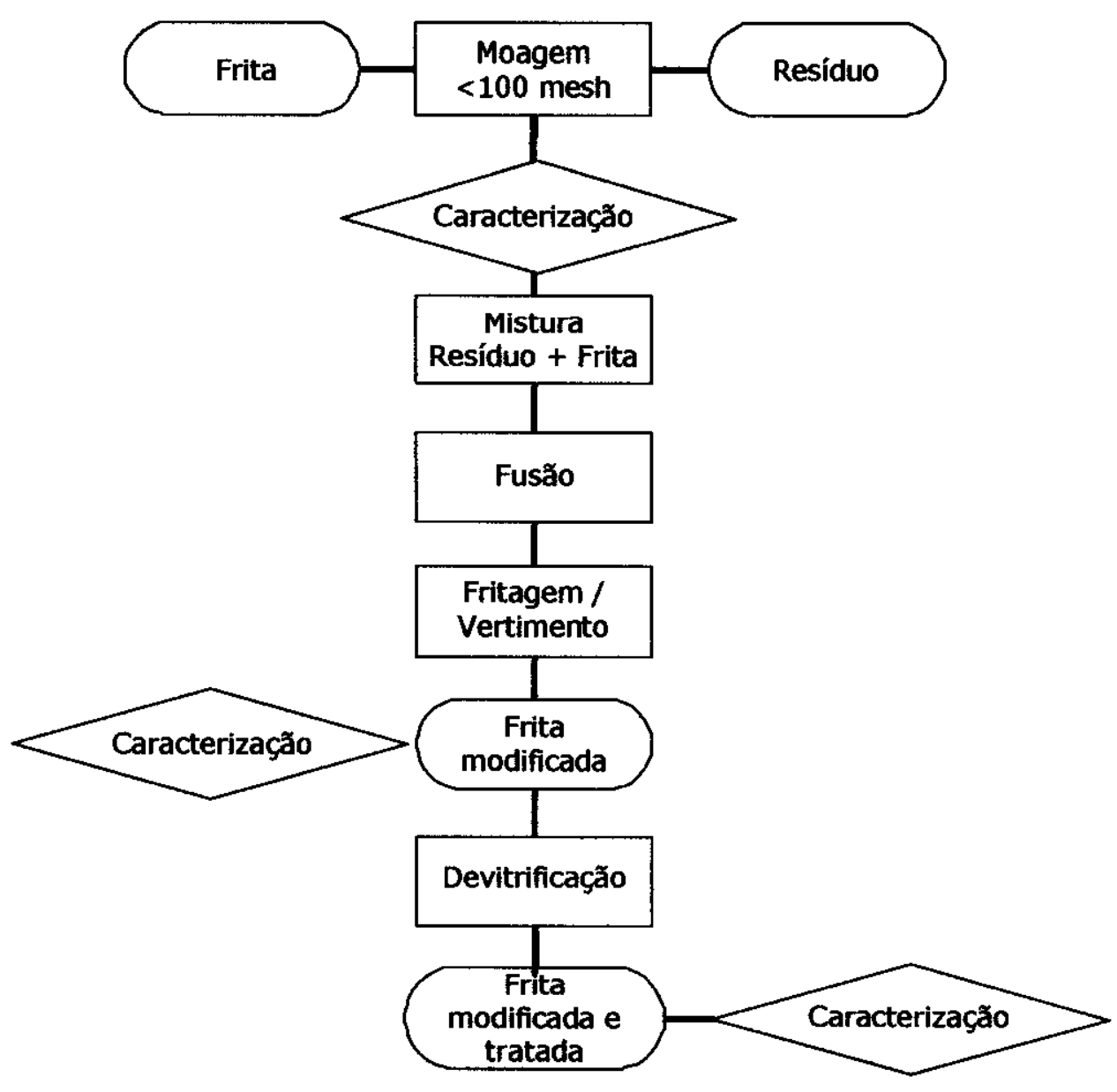

FIGURA 4.1 - Diagrama de blocos das etapas de desenvolvimento experimental do trabalho.

\subsubsection{Amostragem}

A amostra do resíduo foi retirada de um "big bag" ( $\sim 1$ tonelada), e consiste de agregados frágeis. A coleta foi realizada por amostragem, acompanhada de homogeneização para garantir uma boa representatividade e confiabilidade dos resultados.

As fritas foram coletadas de embalagens com aproximadamente $50 \mathrm{~kg}$ de material. 
Em seguida, os materiais foram desagregados a seco em moinho de bolas.

\subsubsection{Desagregação / Moagem}

Esta operação foi realizada para adequar todos os materiais de forma a obter uma maior homogeneidade nas próximas etapas sob o aspecto tamanho de partículas.

As matérias-primas foram submetidas a operações de desagregação e moagem utilizando-se um moinho de bolas, e classificadas por peneiramento em malha \#100mesh $(<150 \mu \mathrm{m})$. Este procedimento foi realizado de acordo com descrito a seguir: a cada parada do moinho, 6h (seis horas), o material foi classificado em peneira granulométrica (< \#100mesh, $150 \mu \mathrm{m}$ ), e a fração retida foi novamente moída até que todo o resíduo, e fritas, passassem pela malha \#100 mesh.

Após esta preparação prévia as amostras receberam as seguintes classificações:

- Resíduo como recebido e classificado, < $150 \mu \mathrm{m}, \mathbf{R}$;

- Resíduo após tratamento térmico de calcinação, RC;

- Frita como recebida e classificada, $<150 \mu \mathrm{m}, \mathbf{F}$.

\subsubsection{Formulação das Composições com adição de Resíduo}

Considerando-se o sistema formador de vidros à base de alumina-cálcia-sílica, as formulações foram calculadas a partir dos componentes majoritários do resíduo " $\mathrm{R}$ " e da frita " $\mathrm{F}$ ".

Com o auxílio do diagrama ternário de equilíbrio de fases, a frita "F" foi localizada, no triângulo de compatibilidade equivalente, Guelenita-Pseudovolastonita-Ranquinita, FIG.4.2. 


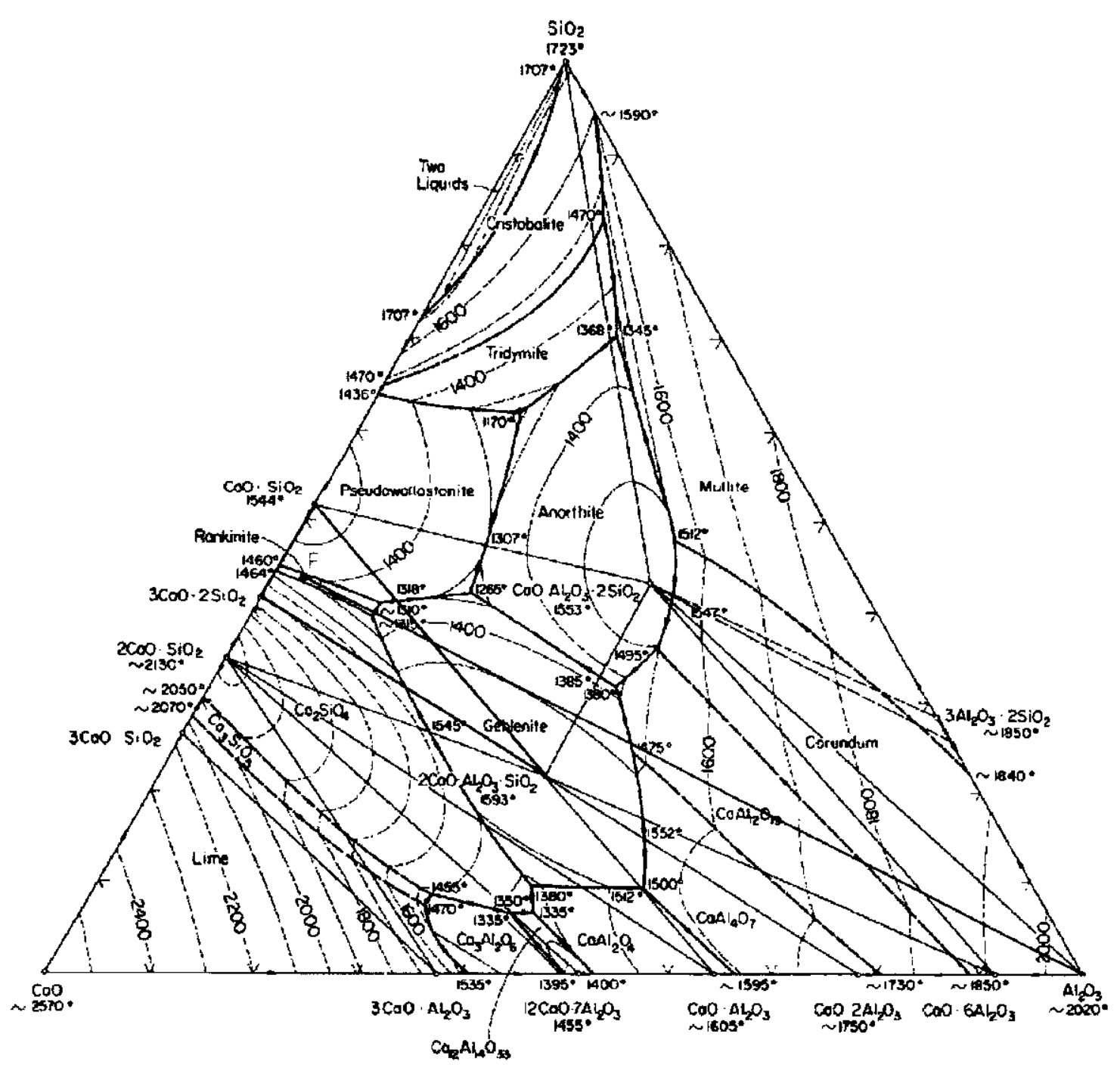

FIGURA 4.2 - Diagrama de equilíbrio de fases do sistema AluminaCálcia-Sílica.

As composições foram calculadas a partir da relação 4.3.1.

$$
\% \mathrm{PFO}=\% \mathrm{PF}+\% \mathrm{PR}
$$

Onde, PFO é a proporção do componente da frita obtida, em porcentagem; PF é a proporção do componente da frita, em porcentagem e PR é a proporção do componente do resíduo, em porcentagem. Foram adicionados 10, 20, 30, 40 e 50\% de resíduo visando verificar a influência da concentração do resíduo no comportamento de fusão e cristalização da frita. 


\subsubsection{Preparação das composições com adição de Resíduo}

As misturas para as composições obtidas foram preparadas a seco em moinho de bolas por 30 minutos e, posteriormente, as composições foram secas em estufa a $110^{\circ} \mathrm{C}$ por $1 \mathrm{~h}$ (uma hora).

0 fato dos dois componentes apresentarem uma granulometria abaixo da malha \#100mesh, < 150 $\mu \mathrm{m}$, auxilia um bom contato entre as partículas facilitando a homogeneização da mistura (TULYAGANOV, 2002).

\subsubsection{Fusão das Composições}

O estudo da influência da temperatura de fusão para as composições foi realizado variando-se a temperatura de $1100^{\circ} \mathrm{C}$ a $1500^{\circ} \mathrm{C}$ com patamar de $2,0 \mathrm{~h}$.

As fusões foram realizadas em forno elétrico vertical tipo Lindberg Blue/M - Blue M eletric CP 56724C, apresentado na FIG. 4.3, em cadinhos de alta alumina com uma porcentagem de aproximadamente $95 \%$ de $\mathrm{Al}_{2} \mathrm{O}_{3}$, (FIG. 4.4). A taxa de aquecimento utilizada foi de $10^{\circ} \mathrm{C} / \mathrm{min}$.

Após o patamar estabelecido, as amostras foram retiradas do forno e vertidas em água destilada em temperatura ambiente para obtenção da frita com incorporação de resíduo.

Estas fritas obtidas foram secas em estufa à $110^{\circ} \mathrm{C}$ por $1 \mathrm{~h}$ (uma hora), moídas / desagregadas em almofariz de porcelana, classificadas em peneira granulométrica malha \#100 mesh, < 150 $\mu \mathrm{m}$; e analisadas pelas técnicas de DRX e FTIR. A técnica de FTIR foi utilizada para avaliar o grau de incorporação do resíduo na frita. 

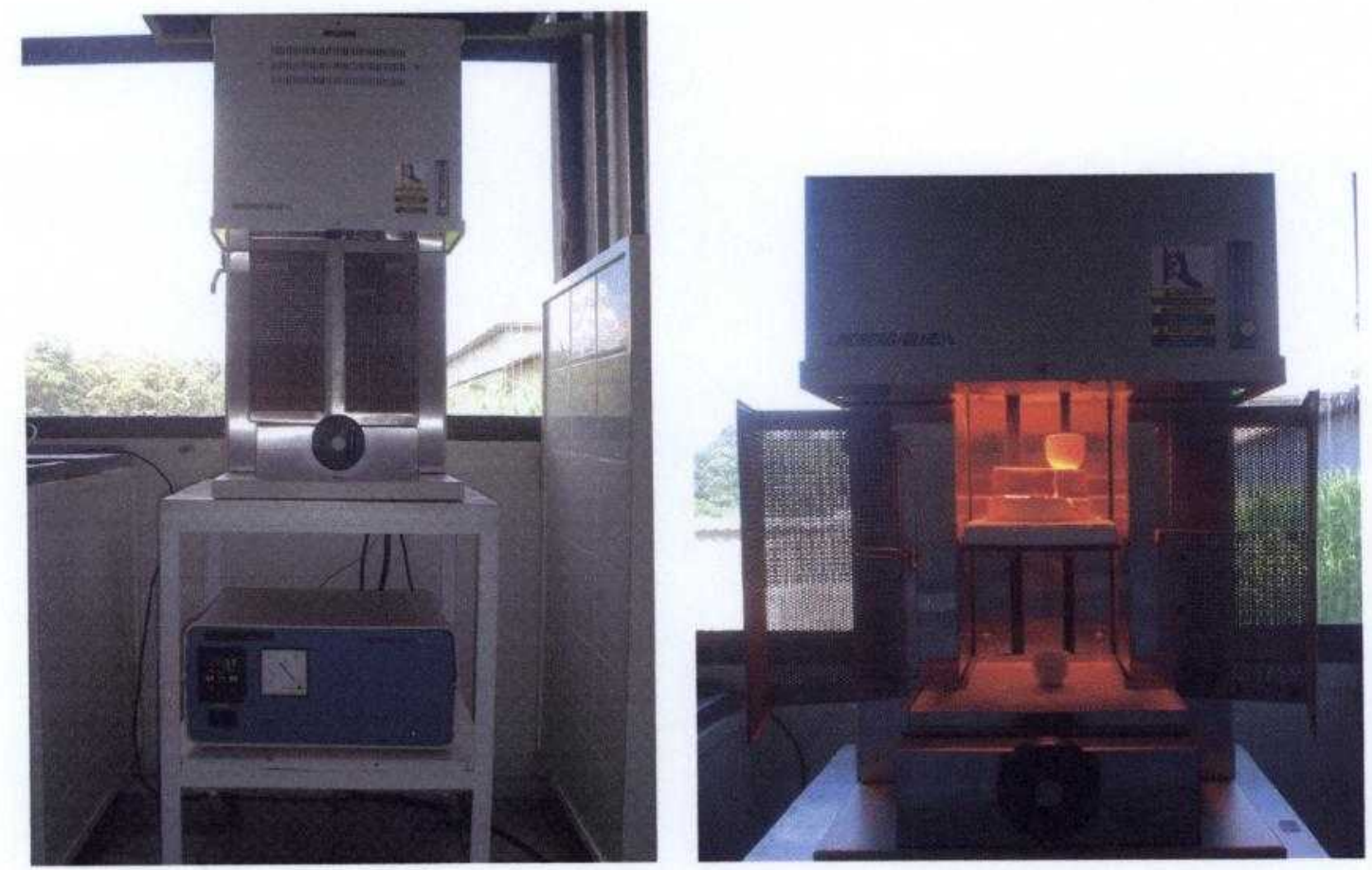

FIGURA 4.3 - Forno Lindberg Blue/M - Blue M eletric CP 56724C.

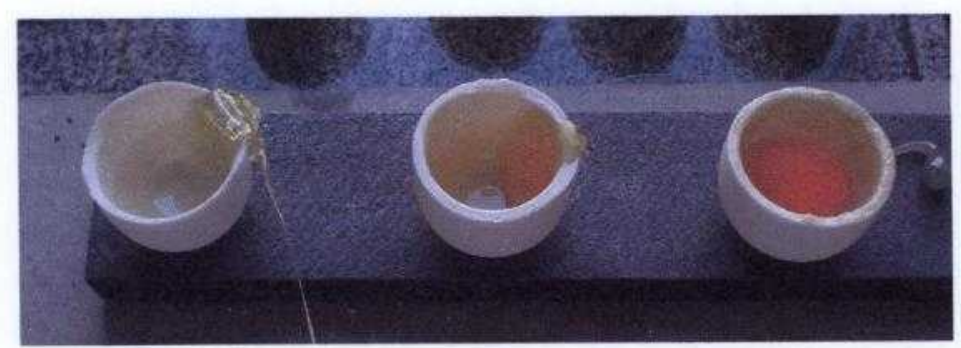

FIGURA 4.4 - Cadinhos utilizados na fusão das fritas modificadas.

As fritas obtidas com incorporação de resíduo na sua composição receberam códigos para facilitar sua identificação. A TAB. 4.1 apresenta esses códigos detalhadamente.

TABELA 4.1 - Códigos para identificar as fritas com incorporação de Resíduo.

\begin{tabular}{cccccc}
\hline Composição & F10R & F20R & F30R & F40R & F50R \\
\hline $\begin{array}{c}\text { Quantidade de resíduo } \\
\text { (em \% mássica) }\end{array}$ & 10 & 20 & 30 & 40 & 50 \\
\hline F - frita; R - resíduo & & & & &
\end{tabular}




\subsubsection{Tratamento de Devitrificação}

Após a fusão, as composições foram moídas e classificadas em peneira granulométrica malha \#100mesh, < 150 $\mu \mathrm{m}$; 0 tratamento térmico foi realizado de forma dinâmica, simulando uma nova sinterização, ou seja, as amostras foram colocadas no forno em temperatura ambiente, a temperatura foi elevada até $900^{\circ} \mathrm{C}$ e mantidas por intervalos de 0,$5 ; 1,0$ ou $2,0 \mathrm{~h}$.

O tratamento de devitrificação foi realizado em forno elétrico tipo mufla da Quimis; as composições moídas foram dispostas em "cacos" de cadinhos de alta alumina e colocadas no interior do forno, a curva de tratamento térmico é apresentada na FIG. 4.5.

Este tratamento foi realizado também na frita $F$ original a fim de verificar o comportamento de cristalização em comparação com às incorporadas com resíduo.

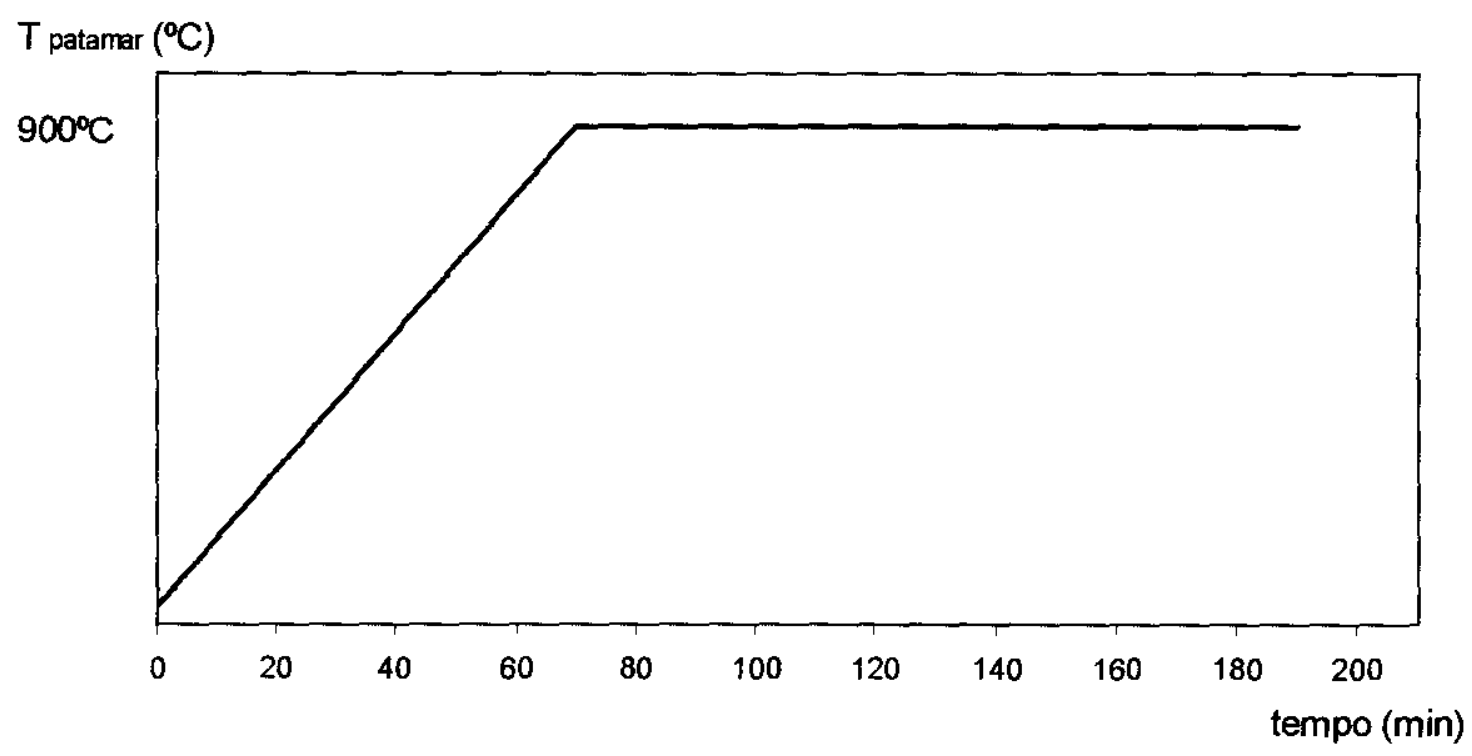

FIGURA 4.5 - Curva de tratamento térmico de devitrificação.

As fritas obtidas com incorporação de resíduo tratadas termicamente receberam códigos para facilitar sua identificação. A TAB. 4.2 apresenta esses códigos detalhadamente. 
TABELA 4.2 - Códigos para identificação das fritas com incorporação de resíduo e tratadas termicamente.

\begin{tabular}{cccc}
\hline Composição & F10R & F20R & F30R \\
\hline $\begin{array}{c}\text { Quantidade de resíduo } \\
\text { (em \% mássica) }\end{array}$ & 10 & 20 & 30 \\
\hline $\begin{array}{c}\text { Temperatura de tratamento térmico } \\
\text { na mufla }\end{array}$ & 900 & 900 & 900 \\
\hline \begin{tabular}{c} 
F - frita; R - resíduo \\
\hline
\end{tabular} & & &
\end{tabular}

As amostras das fritas preparadas e tratadas termicamente foram caracterizadas, identificando-se as fases presentes nas amostras e comparando-as com as calculadas teoricamente. 


\section{RESULTAdOS E discussão}

\subsection{Caracterização das matérias-primas}

\subsubsection{Caracterização do Resíduo Borra Branca (RBB)}

Os resultados da caracterização do resíduo como recebido são apresentados a seguir:

A FIG. 5.1 apresenta uma macrografia ilustrando o aspecto do resíduo como recebido. Trata-se de um pó constituído de agregados de coloração cinza.

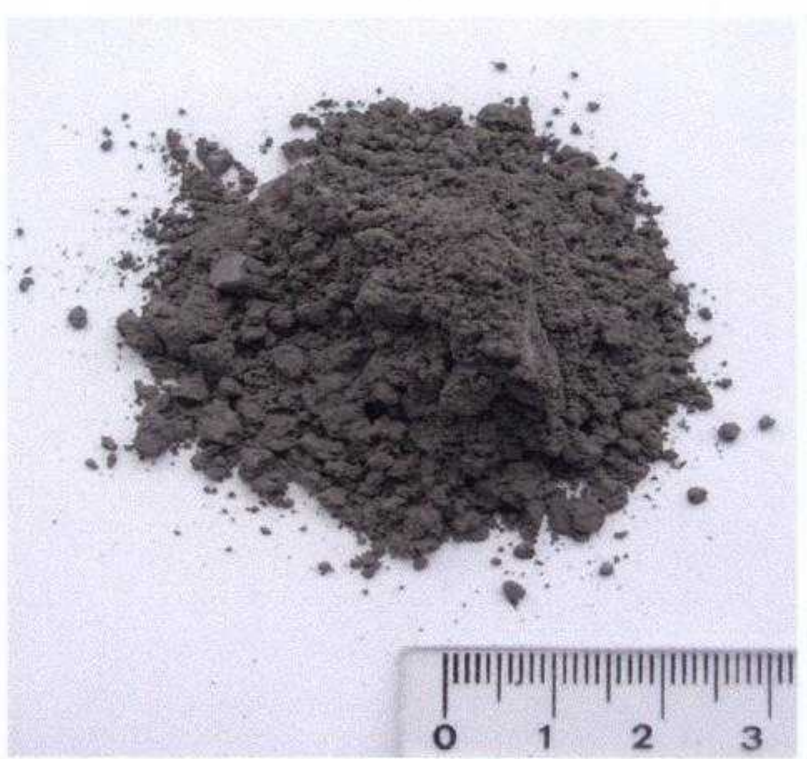

FIGURA 5.1 - Aspecto do Resíduo como recebido.

Ao se realizar a classificação granulométrica em peneira, com o material desagregado em moinho de bolas, pode-se observar na TAB. 5.1 que a maior fração apresenta tamanho de agregado menor que 74 $\mu \mathrm{m}$.

TABELA 5.1 - Distribuição granulométrica por peneiras do Resíduo Borra Branca.

\begin{tabular}{|c|c|c|c|c|c|c|c|}
\hline Peneira & $\begin{array}{c}\# 35 \\
500 \mu \mathrm{m}\end{array}$ & $\begin{array}{c}\# 60 \\
249 \mu \mathrm{m}\end{array}$ & $\begin{array}{c}\# 100 \\
150 \mu \mathrm{m}\end{array}$ & $\begin{array}{c}\# 140 \\
104 \mu \mathrm{m}\end{array}$ & $\begin{array}{l}\# 200 \\
74 \mu \mathrm{m}\end{array}$ & $\begin{array}{l}<\# 200 \\
<74 \mu \mathrm{m}\end{array}$ & Total \\
\hline$\%$ & 0 & 11,35 & 12,83 & 12,34 & 11,15 & 52,32 & 100 \\
\hline
\end{tabular}


Na FIG. 5.2 são apresentadas as micrografias do RBB como recebido, onde se observa 0 aspecto de um agregado com dimensões da ordem de 60 a 80 mícrons na (FIG. 5.2a), constituído por partículas menores de 5 mícrons (FIG. 5.2b).

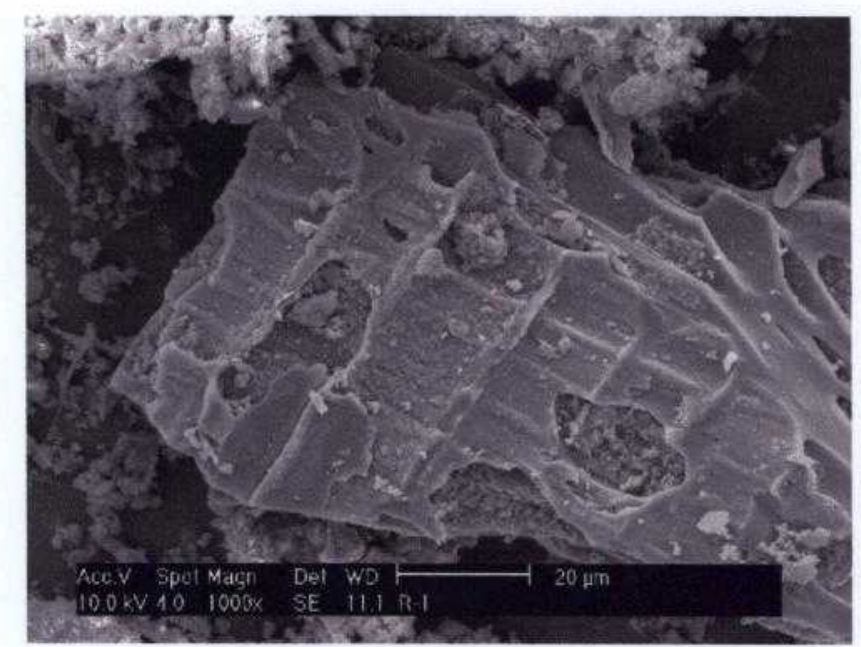

(a)

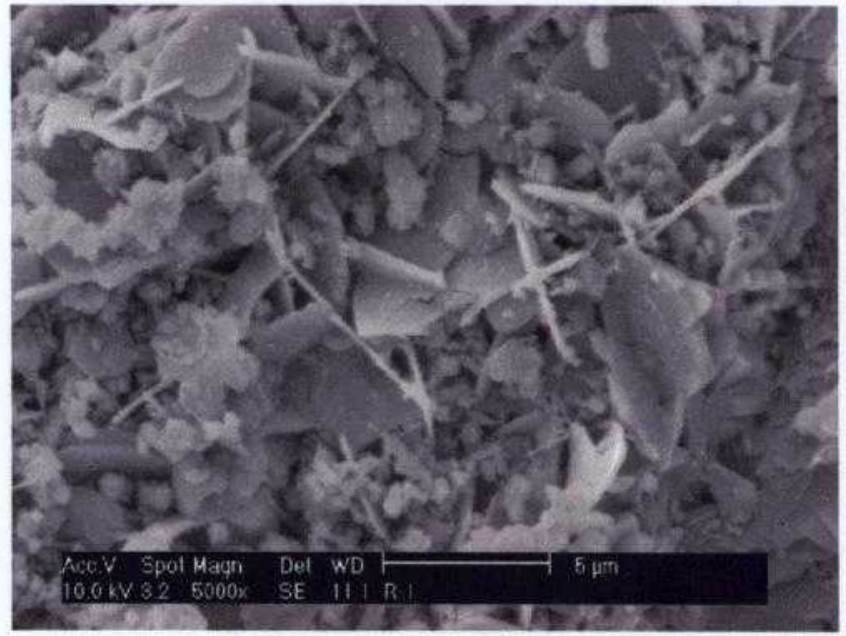

(b)

FIGURA 5.2 - Micrografias obtidas por MEV a partir de amostras de Resíduo Borra Branca como recebido, (a) agregado de resíduo; (b) partículas que compõem os agregados.

Após fazer a desagregação em moinho de bolas por 6 horas, o resíduo apresentou uma distribuição de tamanho de partículas menor que 50 mícrons e com um diâmetro médio $\left(D_{50}\right)$ próximo a 5 mícrons (FIG. 5.4). Sendo, portanto um material bastante friável, com agregados fracamente ligados e com razoável facilidade para esta 
operação. A área de superfície específica do RBB é de $6,65 \mathrm{~m}^{2} / \mathrm{g}$ e, a densidade determinada foi de $3,18 \mathrm{~g} / \mathrm{cm}^{3}$.

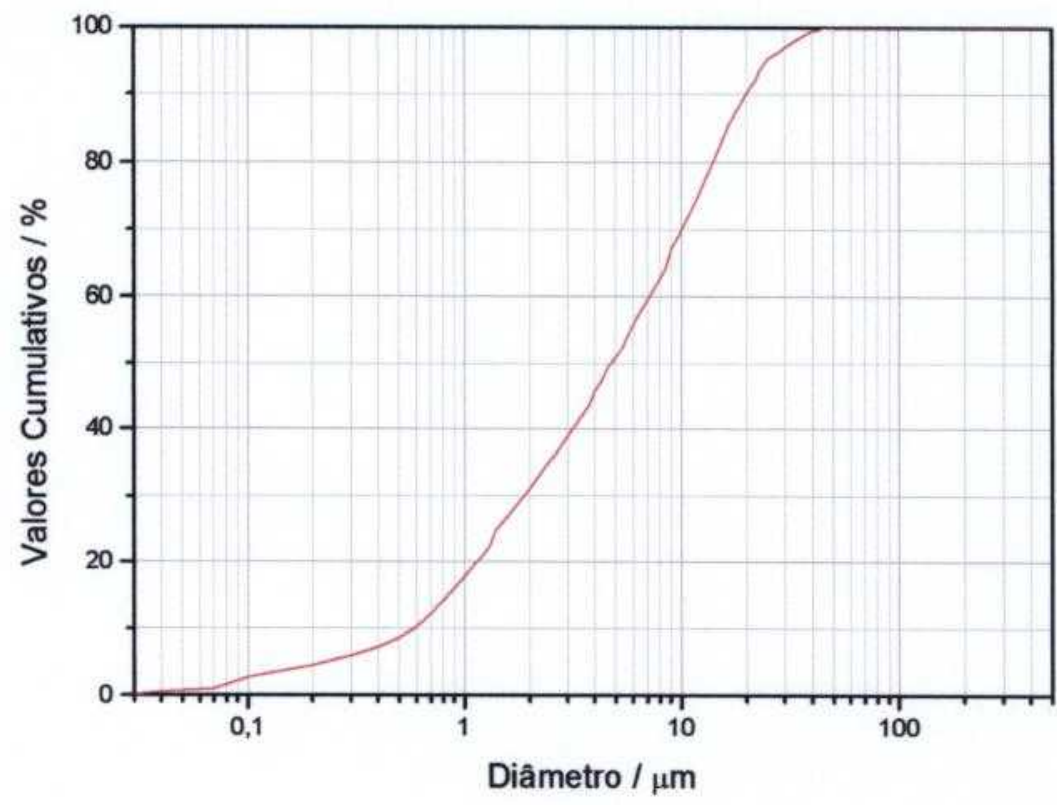

FIGURA 5.3 - Distribuição granulométrica do resido por CILAS.

A composição química do RBB é apresentada na TAB. 5.2, e mostra que se trata de um resíduo com alta porcentagem de alumínio, e em menor quantidade, de magnésio e cálcio. Mesmo sendo um resíduo considerado secundário, ainda apresenta uma alta quantidade de alumínio, pois resulta do tratamento da escória do processo de obtenção do alumínio metálico. O segundo elemento em concentração é o $\mathrm{Mg}$, provavelmente proveniente do processo de redução do alumínio metálico, é derivado da utilização do sal cloreto de magnésio $\left(\mathrm{MgCl}_{3}\right)$ utilizado por empresas de obtenção do alumínio metálico para remoção dos metais indesejáveis do banho (COURTENAY, 2005). Os demais elementos se apresentam em baixa concentração, todas menores que $1,00 \%$. 
TABELA 5.2 - Composição química do resíduo.

\begin{tabular}{cc}
\hline Componente & $\begin{array}{c}\text { RBB } \\
(\% \mathrm{em} \mathrm{mol})\end{array}$ \\
\hline $\mathrm{Si}$ & 0,60 \\
\hline $\mathrm{Al}$ & 92,45 \\
\hline $\mathrm{Fe}$ & 0,68 \\
\hline $\mathrm{Na}$ & 0,67 \\
\hline $\mathrm{K}$ & 0,38 \\
\hline $\mathrm{Zr}$ & 0,27 \\
\hline $\mathrm{Ca}$ & 1,02 \\
\hline $\mathrm{Mg}$ & 3,32 \\
\hline $\mathrm{Ti}$ & 0,18 \\
\hline $\mathrm{Ni}$ & 0,14 \\
\hline Outros & 0,29 \\
\hline
\end{tabular}

$O$ espectro de difração de raios $X$, determinado para a amostra de RBB como recebido é apresentado na FIG. 5.4, onde se identificou a presença de compostos à base de alumínio, óxido e nitreto; e espinélio de magnésio e alumínio, além de, em menor intensidade, de fluorita $\left(\mathrm{CaF}_{2}\right)$, possivelmente utilizado como fluxante no processo de redução do metal (AZOM, 2006).

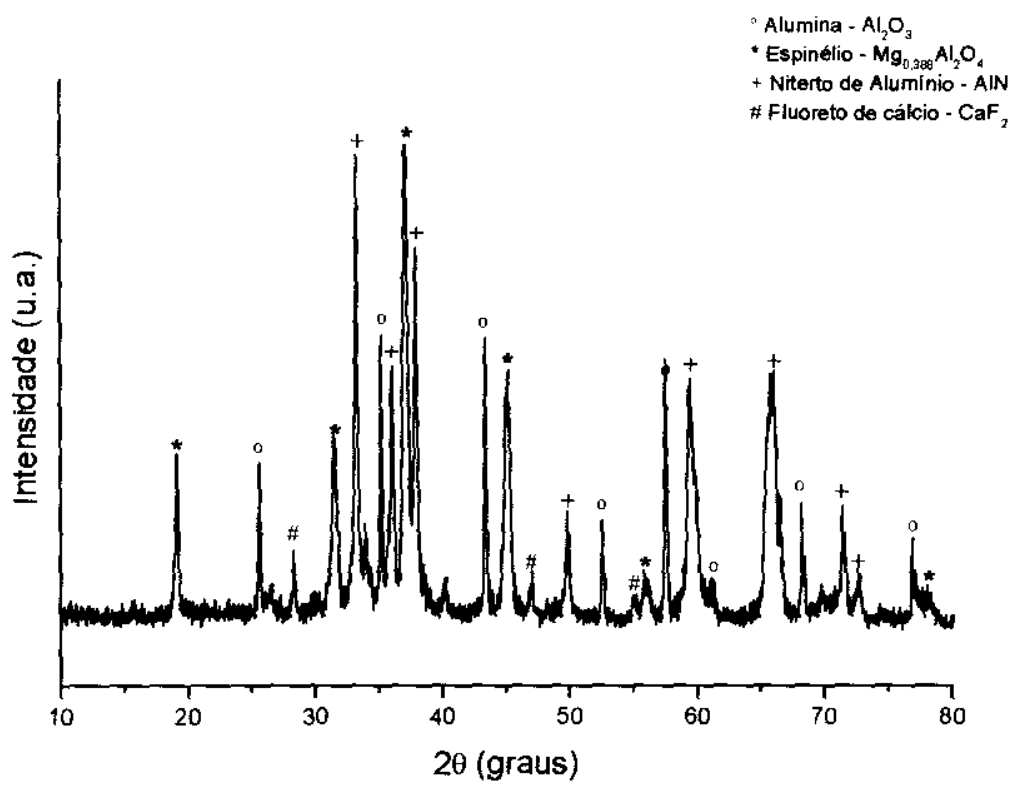

FIGURA 5.4 - Difratograma do resíduo como recebido. 
O comportamento térmico do resíduo puro com o aumento da temperatura, ilustrado pelos resultados da análise térmica, se encontra na FIG. 5.5.

A análise termogravimétrica (ATG) mostra que o material apresenta perda de massa acentuada até mais ou menos $200^{\circ} \mathrm{C}$, relativo à perda de umidade. Com o aumento da temperatura, a perda continua ocorrendo até temperaturas em torno de $635^{\circ} \mathrm{C}(2,8 \%)$. Esta perda de massa pode estar relacionada à decomposição de fluoretos.

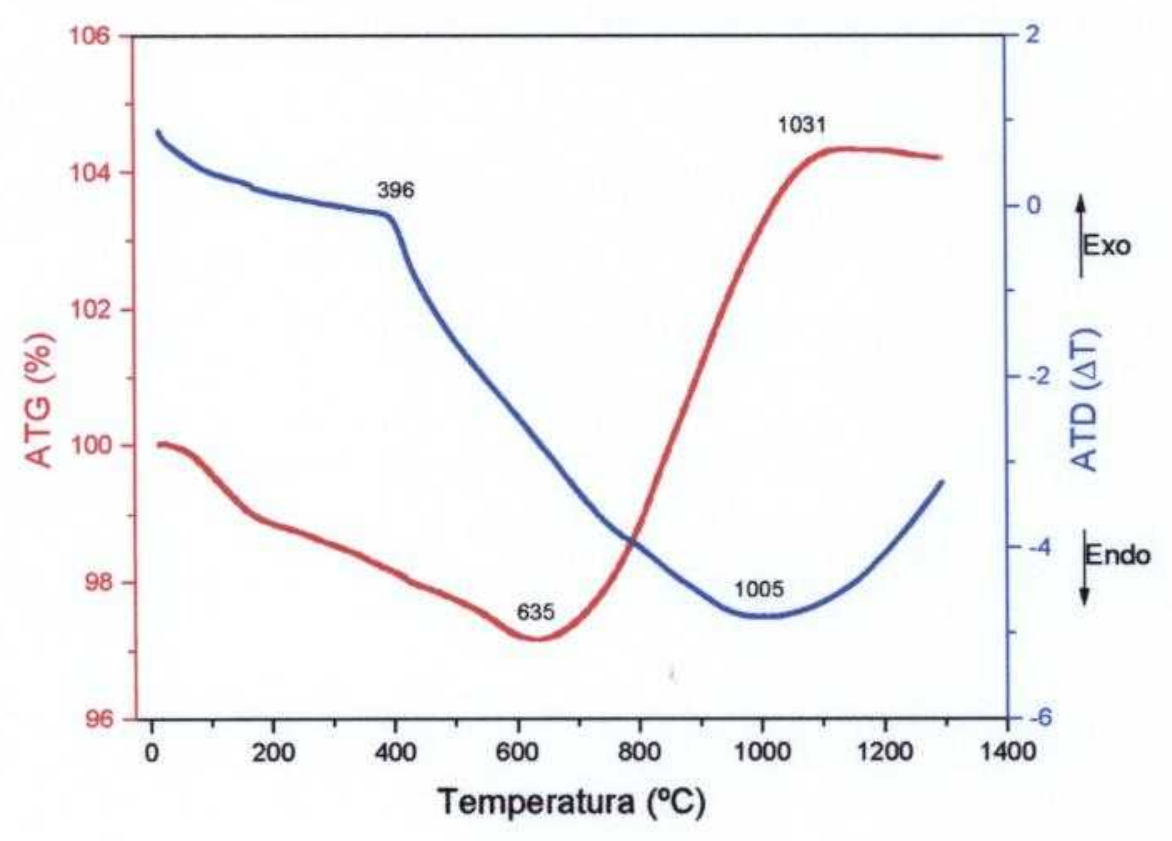

FIGURA 5.5 - Análise térmica do resíduo como recebido.

Considerando que esta análise foi realizada com fluxo normal de ar, com o aumento da temperatura, a partir de $635^{\circ} \mathrm{C}$, tem início um aumento de peso no material, ocorrendo a oxidação do alumínio e o nitreto de alumínio, passando por espécie nitro-oxidadas $\left(\mathrm{AINO}_{\mathrm{x}}\right)$ até se eliminar totalmente nitreto e ter como resultante a formação do óxido de alumínio. Para temperaturas superiores a $1030^{\circ} \mathrm{C}$, o ganho de massa 
tende a diminuir, possivelmente em decorrência da formação de fases mais estáveis da alumina.

Visando confirmar o comportamento observado nas análises térmicas, o RBB como recebido, foi submetido a tratamento térmico na temperatura de $900^{\circ} \mathrm{C}$ por 2 horas. $O$ espectro de difração de raios $X$ obtido a partir de amostras tratadas, nesta temperatura, é apresentado na FIG. 5.6.

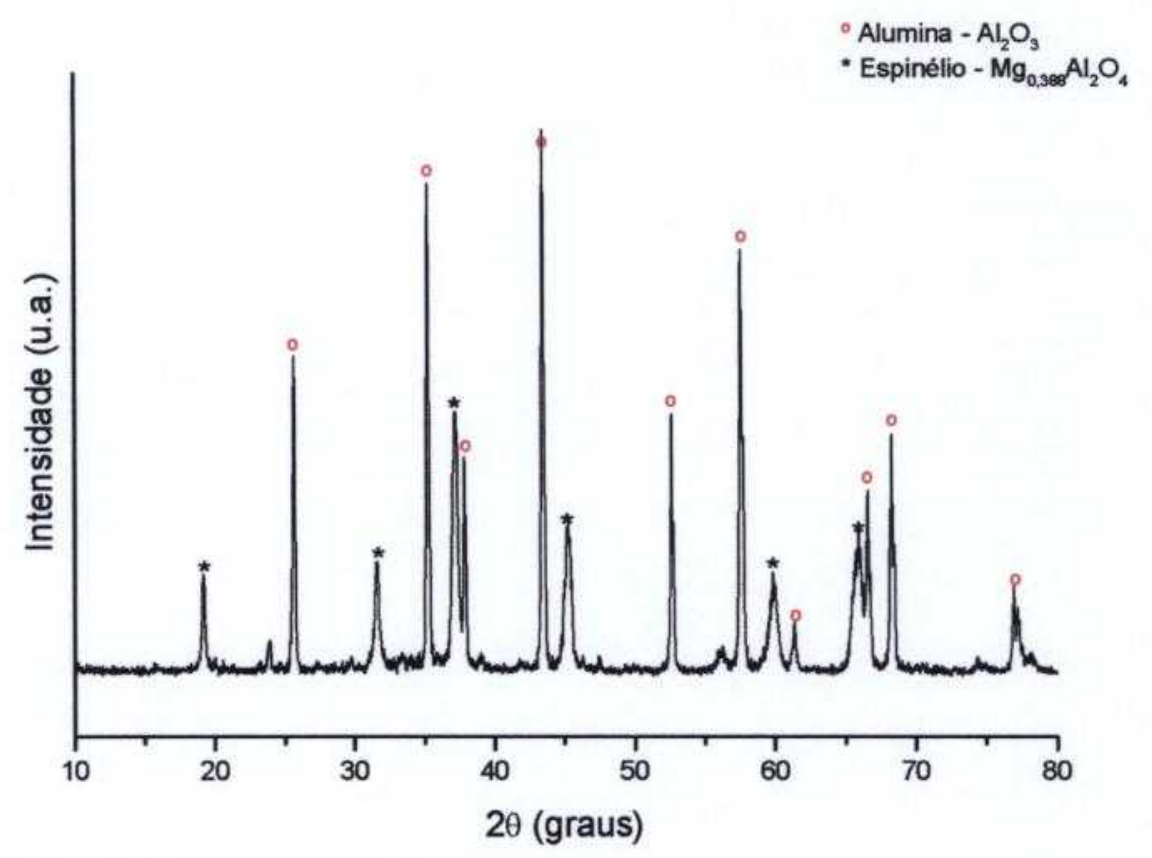

FIGURA 5.6- Difratograma do RBB após tratamento térmico a $900^{\circ} \mathrm{C}$.

Como se observa, após esta temperatura, a amostra revela a predominância dos picos relativos à alumina e espinélio. Não apresentando mais os picos relativos à presença de nitreto de alumino $\mathrm{e}$ nem de fluorita, confirmando que estes tendem a se decompor e oxidar, respectivamente com o aumento da temperatura e atmosfera oxidante.

A FIG. 5.7 apresenta a micrografia obtida por MEV a partir de amostras do resíduo após o tratamento térmico a $900^{\circ} \mathrm{C}$ por 2 horas. 


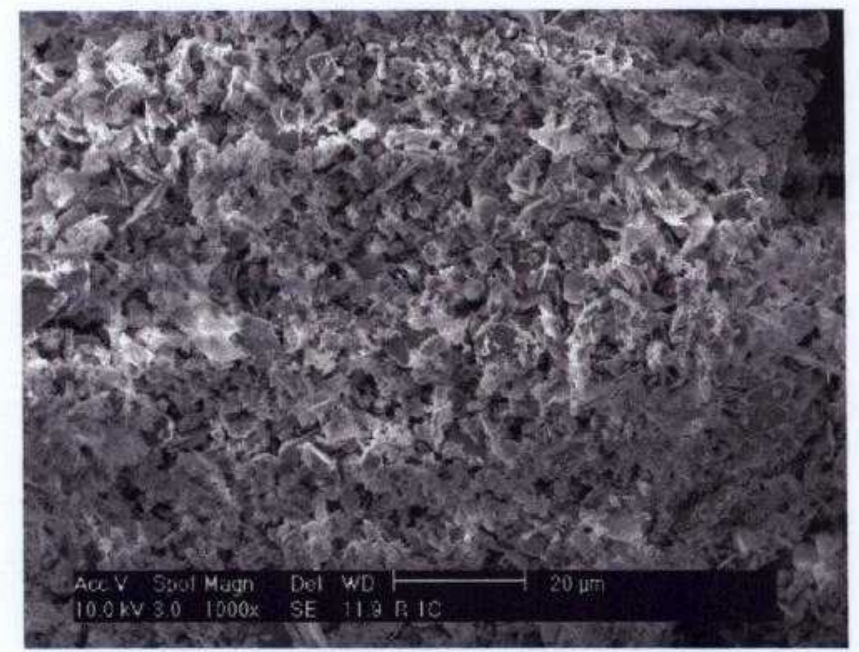

FIGURA 5.7 - Micrografia obtida por MEV, a partir de amostras do RBB, após tratamento térmico a $900^{\circ} \mathrm{C}$.

Após tratamento, não se observa a presença de aglomerados e sim apenas partículas menores e dispersas. Algumas partículas hexagonais de tamanhos variados, semelhantes às partículas de alumina foram observadas na micrografia de MEV, apresentada na FIG. 5.8a. Após a análise por EDS (FIG. 5.8b), foram identificados os elementos com maior intensidade de registro, $\mathrm{Al}$ e $\mathrm{Mg}$, que devem estar relacionados à presença do espinélio $\left(\mathrm{Mg}_{0,388} \mathrm{Al}_{2} \mathrm{O}_{4}\right)$, identificado em análises anteriores (FIG. 5.6).

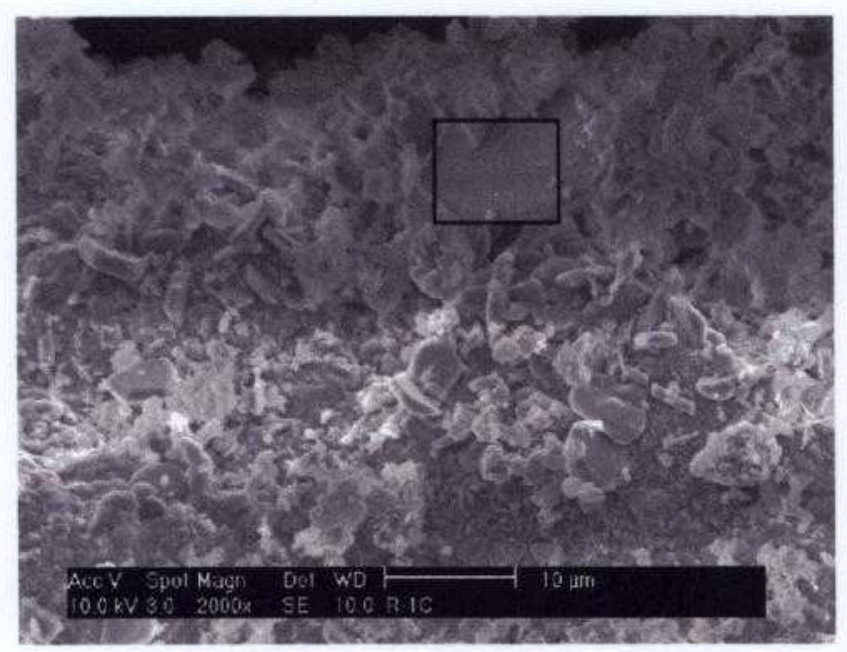

(a)

FIGURA 5.8 (a) - Micrografia obtida por MEV a partir de amostras de RBB, após tratamento térmico a $900^{\circ} \mathrm{C}$. 


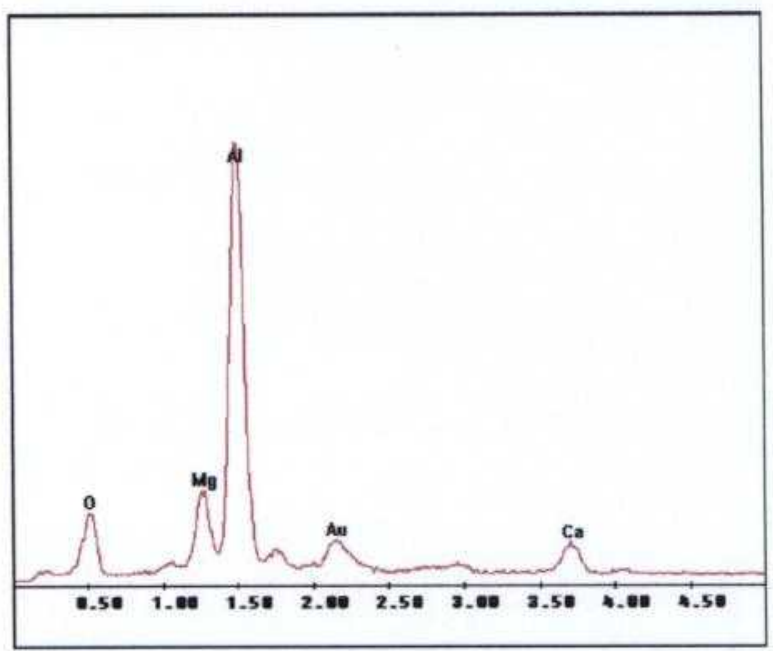

(b)

FIGURA 5.8 (b) - Espectro obtido por EDS, a partir da região assinalada.

\subsubsection{Caracterização da Frita}

A TAB. 5.3 apresenta a composição da frita utilizada neste estudo, possuindo como componentes majoritários o $\mathrm{CaO}$ e $\mathrm{SiO}_{2}$, com baixos teores de $\mathrm{Al}_{2} \mathrm{O}_{3}$ e de $\mathrm{MgO}$.

TABELA 5.3 - Composição química da frita utilizada no trabalho.

\begin{tabular}{cc}
\hline Componente & $\%$ mássica \\
\hline $\mathbf{S i O}_{2}$ & 42,02 \\
\hline $\mathbf{A l}_{2} \mathbf{O}_{3}$ & 2,11 \\
\hline $\mathrm{Fe}_{2} \mathbf{O}_{3}$ & 0,12 \\
\hline $\mathrm{Na}_{2} \mathbf{O}$ & 0,18 \\
\hline $\mathbf{K}_{2} \mathbf{O}$ & 0,20 \\
\hline $\mathbf{Z r O}$ & 1,48 \\
\hline $\mathbf{C a O}$ & 51,41 \\
\hline $\mathbf{M g O}$ & 2,32 \\
\hline $\mathbf{Z n O}$ & 0,15 \\
\hline
\end{tabular}

A frita foi cominuída, e classificada granulometricamente em peneira malha \# 100mesh $(<150 \mu \mathrm{m})$. 
A representação da composição química da frita, utilizando-se o diagrama de equilíbrio $\left(\mathrm{Al}_{2} \mathrm{O}_{3}-\mathrm{CaO}-\mathrm{SiO}_{2}\right)$, foi realizada calculando-se a composição estimada, levando-se em conta apenas os componentes majoritários. Observa-se que a frita pertence ao campo de cristalização primária da ranquinita, no triângulo de compatibilidade de cristalização dos compostos Pseudovolastonita, Ranquinita e Guelenita, como se apresenta na FIG. 5.9.

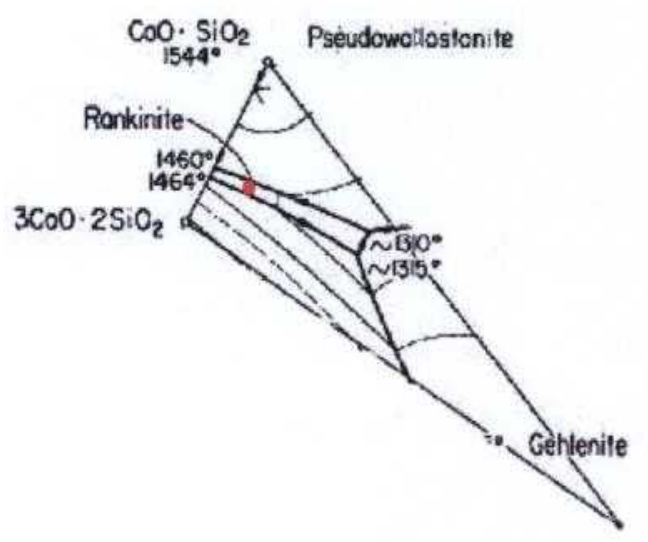

FIGURA 5.9 - Triângulo de compatibilidade do diagrama de equilíbrio de fases do sistema $\mathrm{Al}_{2} \mathrm{O}_{3}-\mathrm{CaO}-\mathrm{SiO}_{2}$ localizando a frita a partir dos componentes majoritários.

Na FIG. 5.10 apresenta-se o difratograma de raios $X$ realizado na frita. 


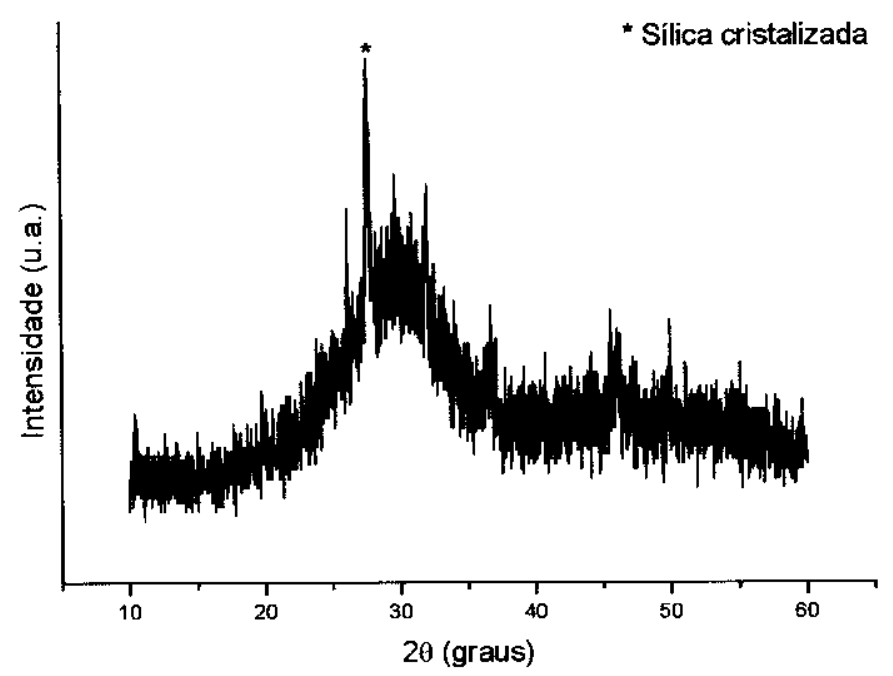

FIGURA 5. 10 - Difratograma da frita.

O difratograma, típico de um material amorfo à base de silício, apresenta um pico mais intenso em $28^{\circ}$, que está relacionado à sílica cristalizada.

O espectro de FTIR (FIG. 5.11) realizado na frita apresenta os picos característicos de uma estrutura vítrea à base de silicatos.

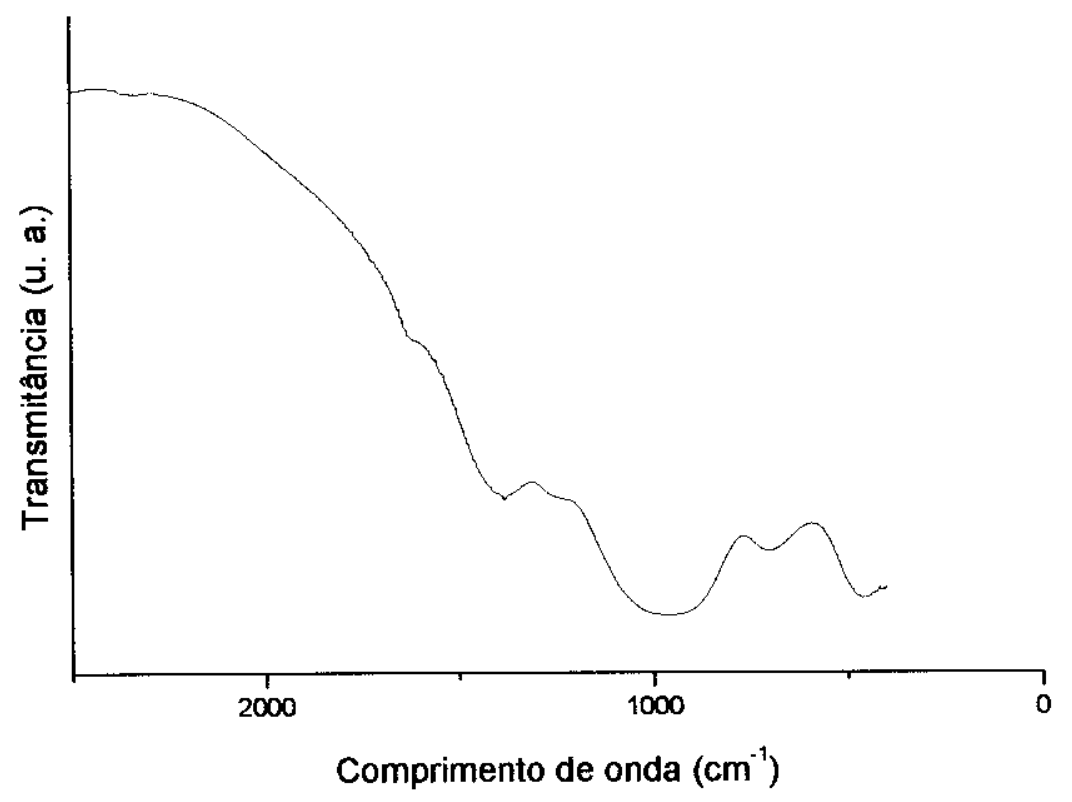

FIGURA 5.11 - Espectro de FIIR da frita. 
0 modo vibracional, aproximadamente a $460 \mathrm{~cm}^{-1}$ refere-se à ligação Si-O-Si; a ausência de pico próximo a $590 \mathrm{~cm}^{-1}$ indica que os possíveis óxidos metálicos não estão segregados, o modo próximo a $700 \mathrm{~cm}^{-1}$ não foi identificado. A ausência de modo à $780 \mathrm{~cm}^{-1}$ já indica alteração na rede; o modo vibracional verificado a aproximadamente $960 \mathrm{~cm}^{-1}$ indica uma modificação estrutural na rede, e o pico próximo a $1200 \mathrm{~cm}^{-1}$ é relativo à rede de vidro, ligações Si-O.

A análise de ATD da frita apresenta um pico endotérmico indicando uma temperatura de transição vítrea $(\mathrm{Tg})$ a $680^{\circ} \mathrm{C}$, e um pico exotérmico indicando uma temperatura de cristalização (Tp) bem definido, na temperatura de $830^{\circ} \mathrm{C}$ (FIG. 5.12). Deste modo, a temperatura de nucleação da frita é aproximadamente $800^{\circ} \mathrm{C}$, temperatura pouco abaixo da temperatura de cristalização (DUAN, R. G. et al., 1998).

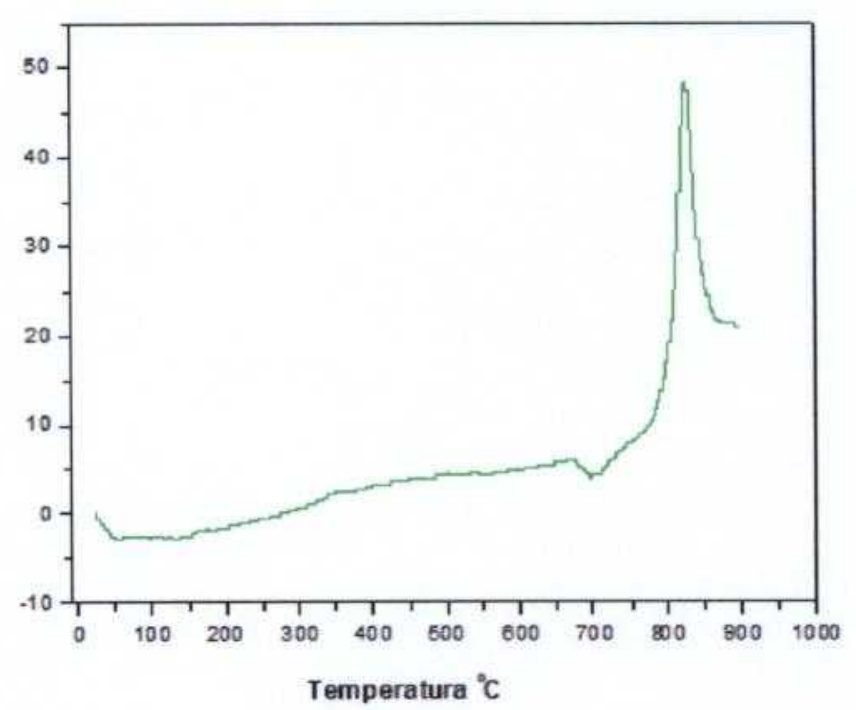

FIGURA 5.12 - Análise Térmica Diferencial da frita.

A morfologia da frita observada por análise de MEV, FIG. 5.13, mostra um aspecto da superfície de um fragmento da frita indicando se tratar de um material amorfo, sem presença de cristais ou nucleação de fase cristalina, observáveis até a resolução da análise. 


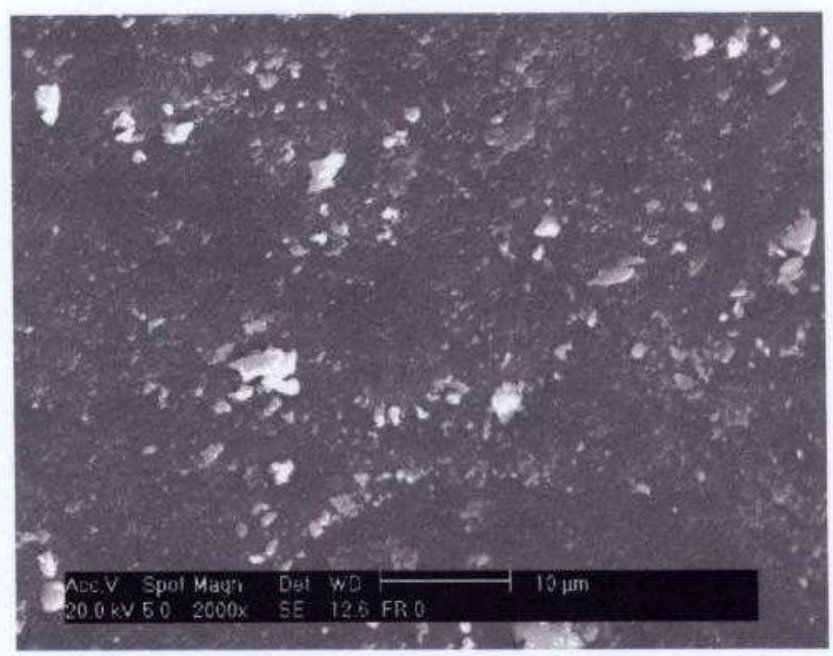

FIGURA 5.13 - Micrografia a partir da superfície de fragmento da frita, como recebida (imagem obtida por MEV).

\subsection{Tratamento Térmico da Frita}

As amostras de frita foram tratadas termicamente a $900^{\circ} \mathrm{C}$ apresentando formação de fases cristalinas após 0,$5 ; 1,0$ e 2,0 horas, FIG. 5.14.

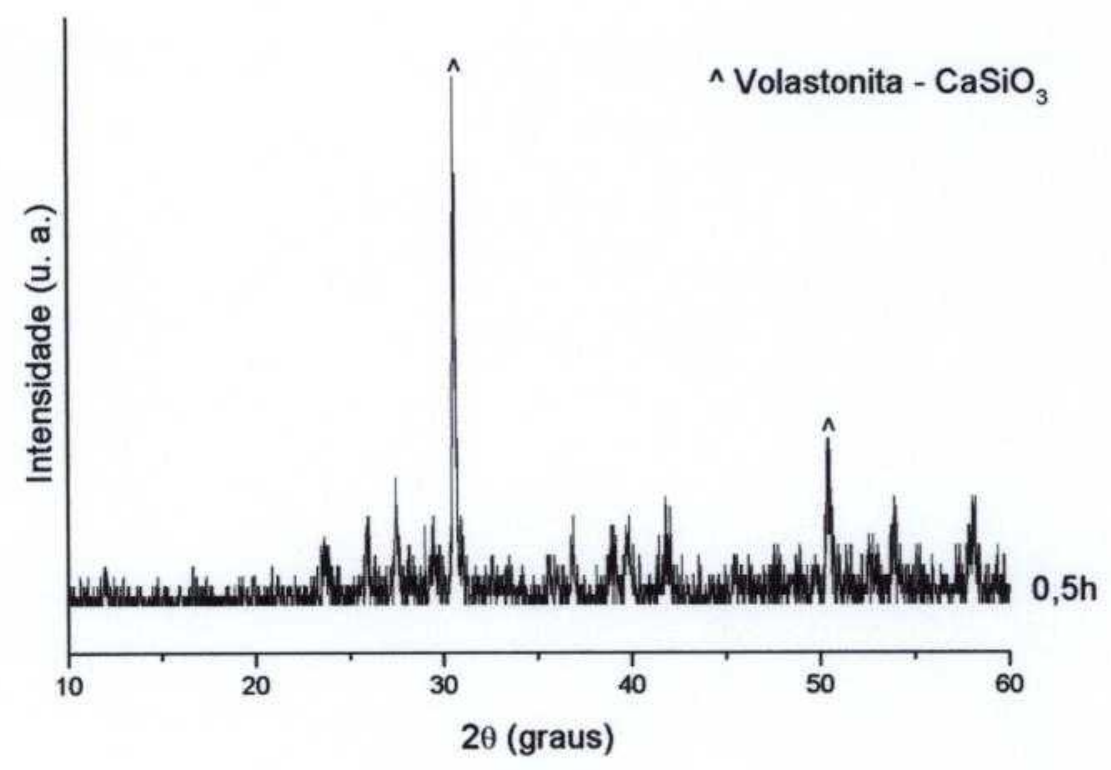

(a) 
O tratamento térmico de devitrificação por 0,5 horas apresenta um início de cristalização da fase volastonita, com picos de baixa intensidade.

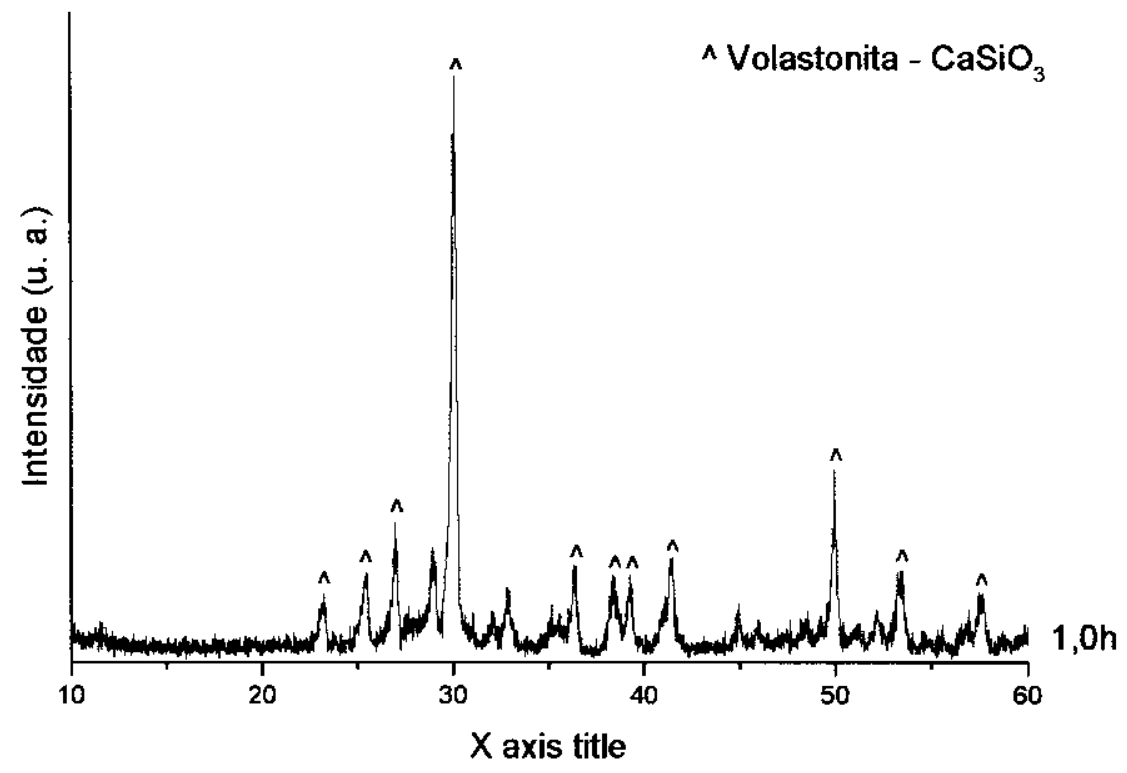

(b)

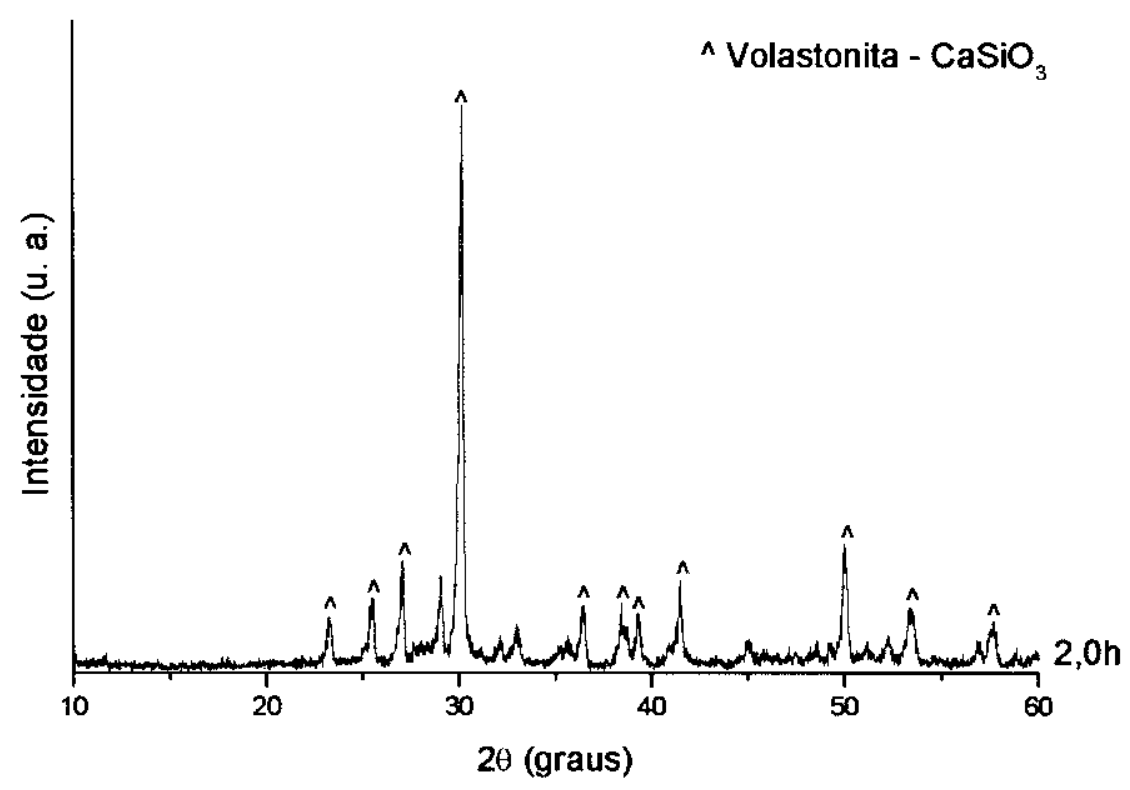

(c)

FIGURA 5.14 -Difratograma de frita tratada a $900^{\circ} \mathrm{C}$ por 0,5 (a); 1,0

(b) e 2,0 horas (c). 
As fritas tratadas por 1,0 e 2,0 horas apresentam picos mais intensos e definidos.

\subsection{Composições da Frita com adição de Resíduo}

Com o objetivo de adicionar o RBB à frita, e, para acompanhar o comportamento funcional deste, fez-se adições criteriosas do resíduo, tendo como base a composição do diagrama de equilíbrio de fases dos componentes majoritários, fazendo-se as possíveis equivalências funcionais de composição, mantendo-se o sistema dentro das proporções calculadas.

As composições calculadas e estudadas neste trabalho estão apresentadas na TAB. 5.4, onde se observa que a adição de resíduo altera consideravelmente o conteúdo de alumina na composição modificada. Apesar da relativamente alta concentração de magnésia no resíduo, com a incorporação de resíduo na frita a porcentagem de MgO na composição final é pouco incrementada.

TABELA 5.4 - Composições calculadas da frita com adição de resíduo.

\begin{tabular}{|c|c|c|c|c|c|}
\hline \multirow{2}{*}{ Componente } & \multicolumn{5}{|c|}{ Composições estudadas (\% mássica) } \\
\hline & $10 \%$ R & $20 \%$ R & $30 \%$ R & $40 \% \mathrm{R}$ & $50 \%$ R \\
\hline $\mathrm{SiO}_{2}$ & 37,94 & 33,86 & 29,78 & 25,69 & 21,61 \\
\hline $\mathbf{A l}_{\mathbf{2}} \mathbf{O}_{3}$ & 10,77 & 19,43 & 28,10 & 36,77 & 45,45 \\
\hline $\mathrm{Fe}_{2} \mathrm{O}_{3}$ & 0,14 & 0,16 & 0,18 & 0,20 & 0,22 \\
\hline $\mathrm{Na}_{2} \mathrm{O}$ & 0,24 & 0,30 & 0,36 & 0,41 & 0,47 \\
\hline $\mathrm{K}_{2} \mathrm{O}$ & 0,21 & 0,21 & 0,22 & 0,22 & 0,23 \\
\hline $\mathrm{ZrO}_{2}$ & 1,34 & 1,21 & 1,08 & 0,95 & 0,82 \\
\hline $\mathrm{CaO}$ & 46,42 & 41,43 & 36,43 & 31,42 & 26,41 \\
\hline Mgo & 2,80 & 3,28 & 3,75 & 4,23 & 4,71 \\
\hline Zno & 0,14 & 0,13 & 0,11 & 0,10 & 0,09 \\
\hline
\end{tabular}

Incorporando-se de 10 a $40 \%$ de resíduo, as composições encontram-se dentro do campo de cristalização primária da guelenita 
(2 $\left.\mathrm{CaO} \cdot \mathrm{Al}_{2} \mathrm{O}_{3} \cdot \mathrm{SiO}_{2}\right)$, alterando-se apenas os triângulos de compatibilidade onde está localizada (FIG. 5.15a, FIG. 5.15b e 5.15c); com a adição de $50 \%$ de resíduo, a composição está localizada no campo de cristalização primária do composto $\mathrm{CaO} \cdot 6 \mathrm{Al}_{2} \mathrm{O}_{3}$, localizado no triângulo de compatibilidade da Anortita $\left(\mathrm{CaO} \cdot \mathrm{Al}_{2} \mathrm{O}_{3} \cdot 2 \mathrm{SiO}_{2}\right.$ ), Guelenita e 0 composto $\mathrm{CaO} \cdot 6 \mathrm{Al}_{2} \mathrm{O}_{3}$ (FIG. 5.15c).

A TAB. 5.5 apresenta o comportamento de fusão de amostras com algumas adições de resíduo, após fusão em várias temperaturas, ilustrando também, as macrografias referentes aos cadinhos utilizados para cada condição experimental.

Observa-se nesta Tabela, que adicionando-se até $30 \%$ em massa de resíduo pode se obter um material com boas características de vertimento, quando a fusão é realizada a $1300^{\circ} \mathrm{C}$. Para a comprovação desta temperatura, realizou-se para as mesmas composições, a fusão a temperatura de $1500^{\circ} \mathrm{C}$ e verificou-se que para todas as composições houve reação entre o banho (o fundido) e 0 cadinho. Para adições de 40 e $50 \%$ em massa de resíduo na frita, e visto que o resíduo é constituído basicamente de alumina, observou-se que estas composições necessitam de temperaturas mais elevadas para fusão e vertimento, não sendo, portanto, interessante para o processo sob o ponto de vista tanto energético como econômico.

A temperatura de $1300^{\circ} \mathrm{C}$ foi suficiente para permitir a fusão de composições contendo até $30 \%$ em massa de RBB como recebido na frita. 


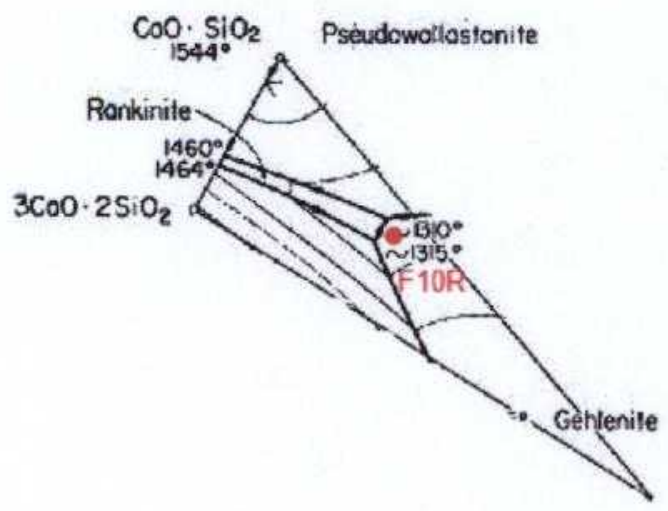

(a)

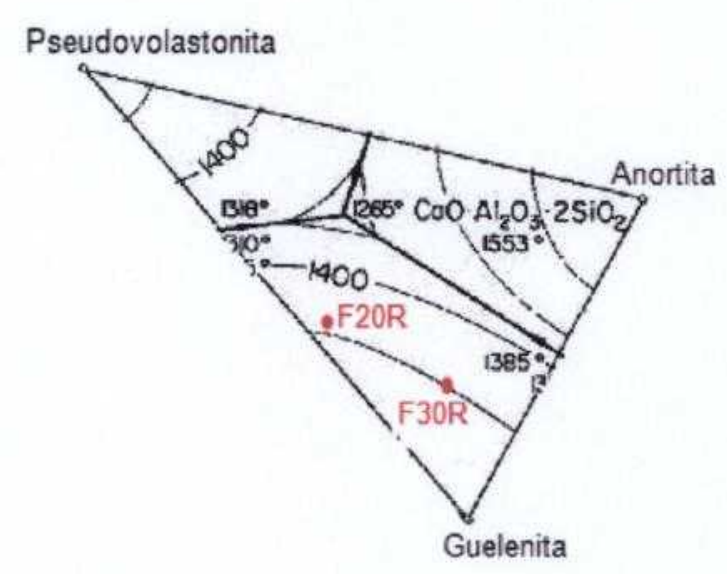

(b)

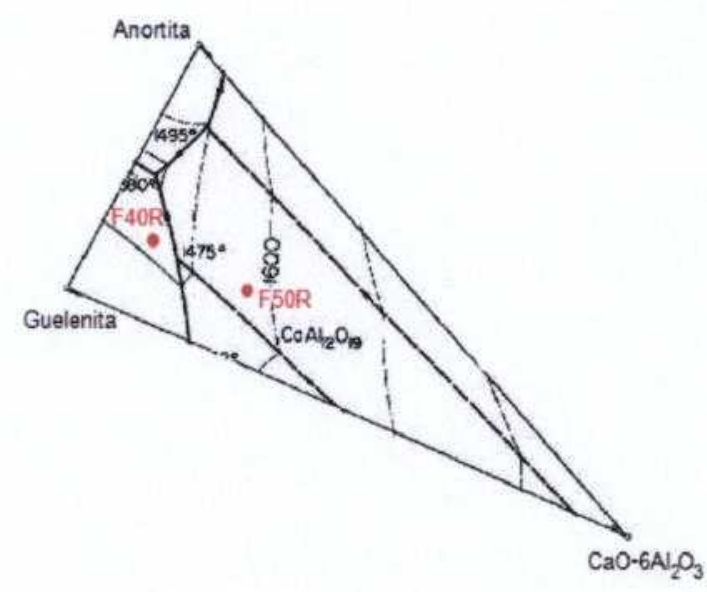

(c)

FIGURA 5.15 - Triângulos de compatibilidade do diagrama de equilíbrio de fases do sistema $\mathrm{Al}_{2} \mathrm{O}_{3}-\mathrm{CaO}-\mathrm{SiO}_{2}$, onde se localizam as composições com F10R (a), F20R e F30R (b), e F40R e F50R(c), respectivamente. 
TABELA 5.5 - Comportamento da frita em diferentes temperaturas de fusão e porcentagem de adição de resíduo.

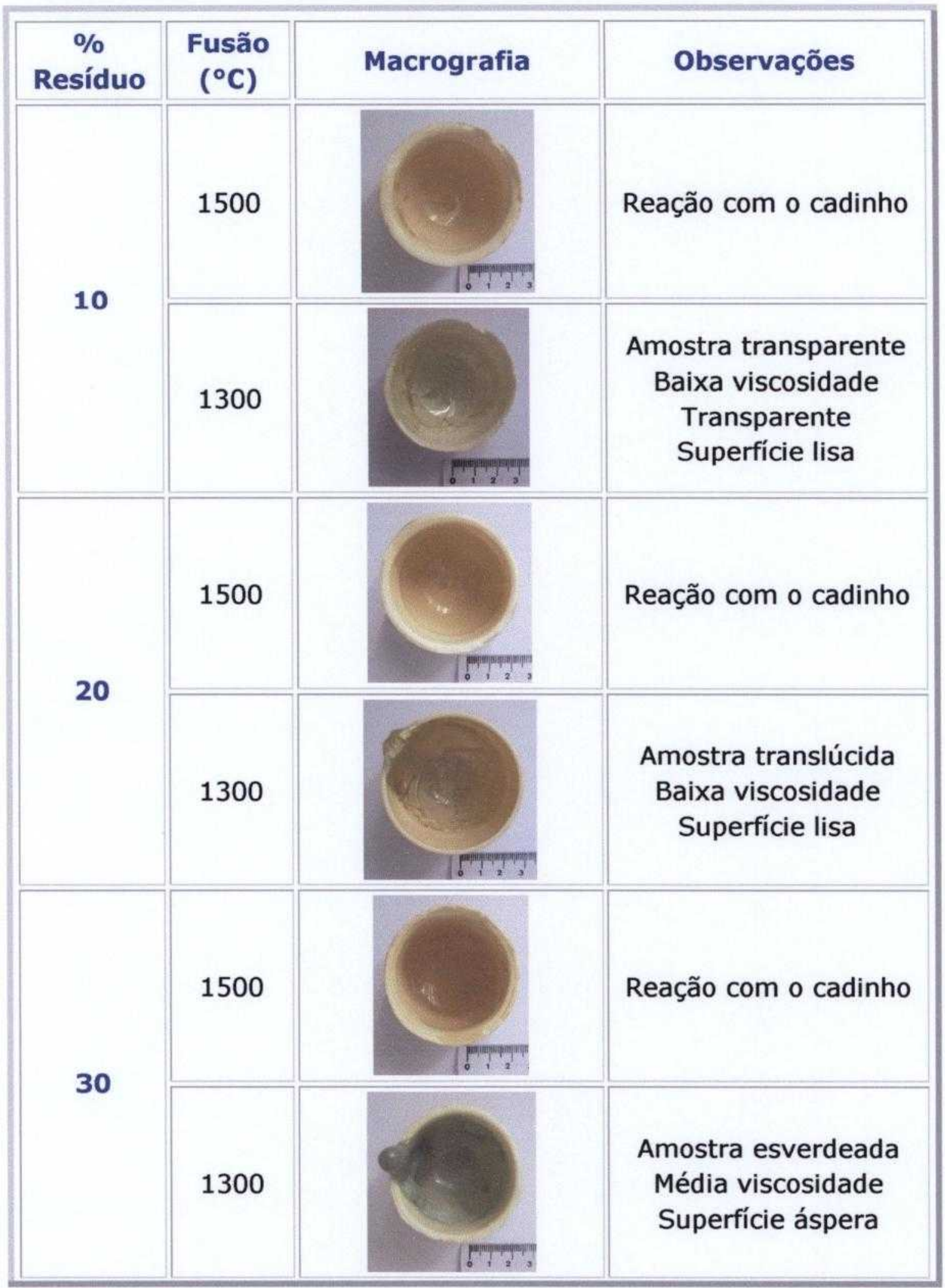




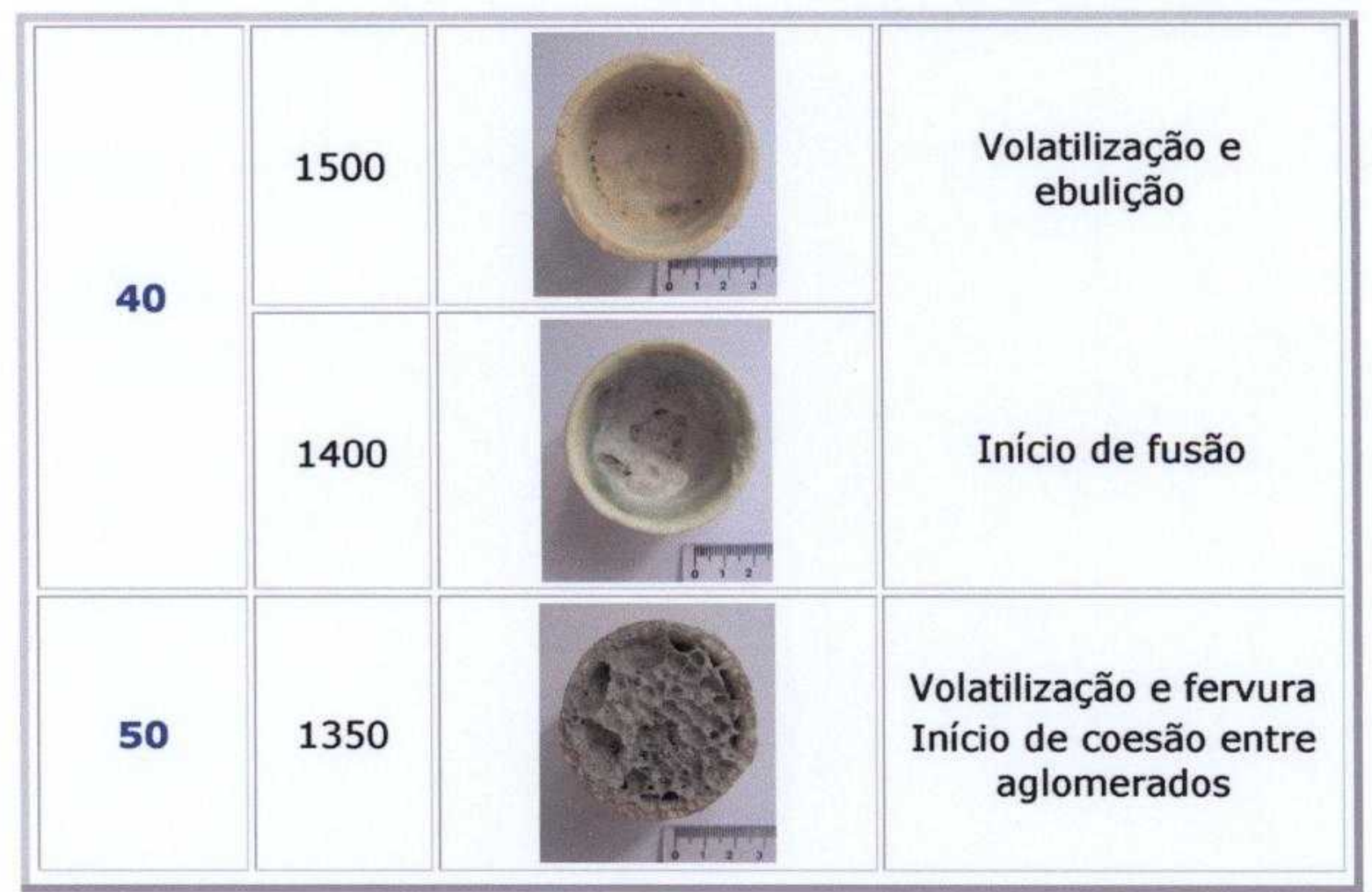

A FIG. 5.16 apresenta os difratogramas obtidos a partir de amostras das composições FR10, FR20 e, FR30 após a fusão a $1300^{\circ} \mathrm{C}$ por 2 horas, onde se observa que estas composições, de uma forma geral apresentam um aspecto de material completamente vítreo silicato, sem exibir nenhum pico relativo a alguma fase cristalina, tanto às presentes no resíduo como às remanescentes de processos posteriores de cristalização. 


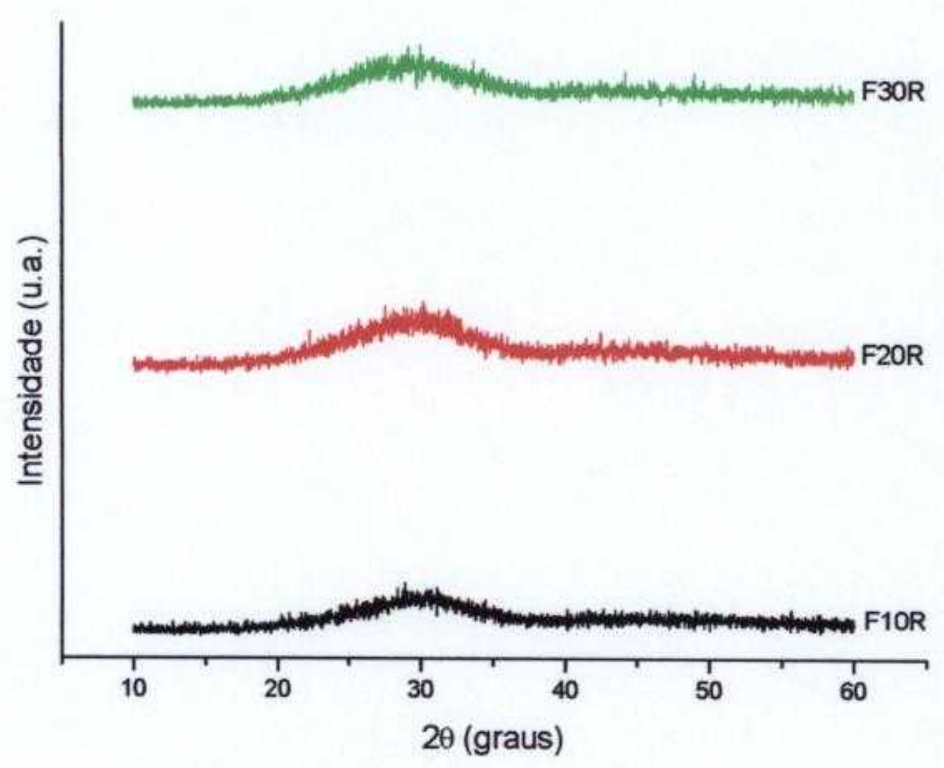

FIGURA 5.16 - Difratogramas das composições F10R (preto), F20R (vermelho) e F30R (verde), após fusão a $1300^{\circ} \mathrm{C} / 2 \mathrm{~h}$

A FIG. 5.17 que ilustra os espectros de infravermelho (FTIR) a partir das composições estudadas.

0 modo vibracional, aproximadamente a $460 \mathrm{~cm}^{-1}$ refere-se à ligação $\mathrm{Si}-\mathrm{O}-\mathrm{Si}$; a ausência de pico próximo a $590 \mathrm{~cm}^{-1}$ indica que os possíveis óxidos metálicos não estão segregados, o modo vibracional próximo a $700 \mathrm{~cm}^{-1}$ não foi identificado. A ausência de modo à $780 \mathrm{~cm}^{-1}$ já indica alteração na rede; o modo verificado a aproximadamente $960 \mathrm{~cm}^{-1}$ indica modificação na rede, e o pico próximo a $1200 \mathrm{~cm}^{-1}$ é relativo à rede de vidro, ligações Si-O.

$\mathrm{Na}$ amostra da composição F30R aparecem alguns modos vibracionais que sugerem modificação na rede, são eles: $560 \mathrm{~cm}^{-1}, 720$ $\mathrm{cm}^{-1}, 960 \mathrm{~cm}^{-1}$ e $1070 \mathrm{~cm}^{-1}$. Provavelmente a incorporação de $30 \%$ em massa de resíduo interfere na rede, com quebra de ligações relacionadas a estrutura vítrea da frita base. 


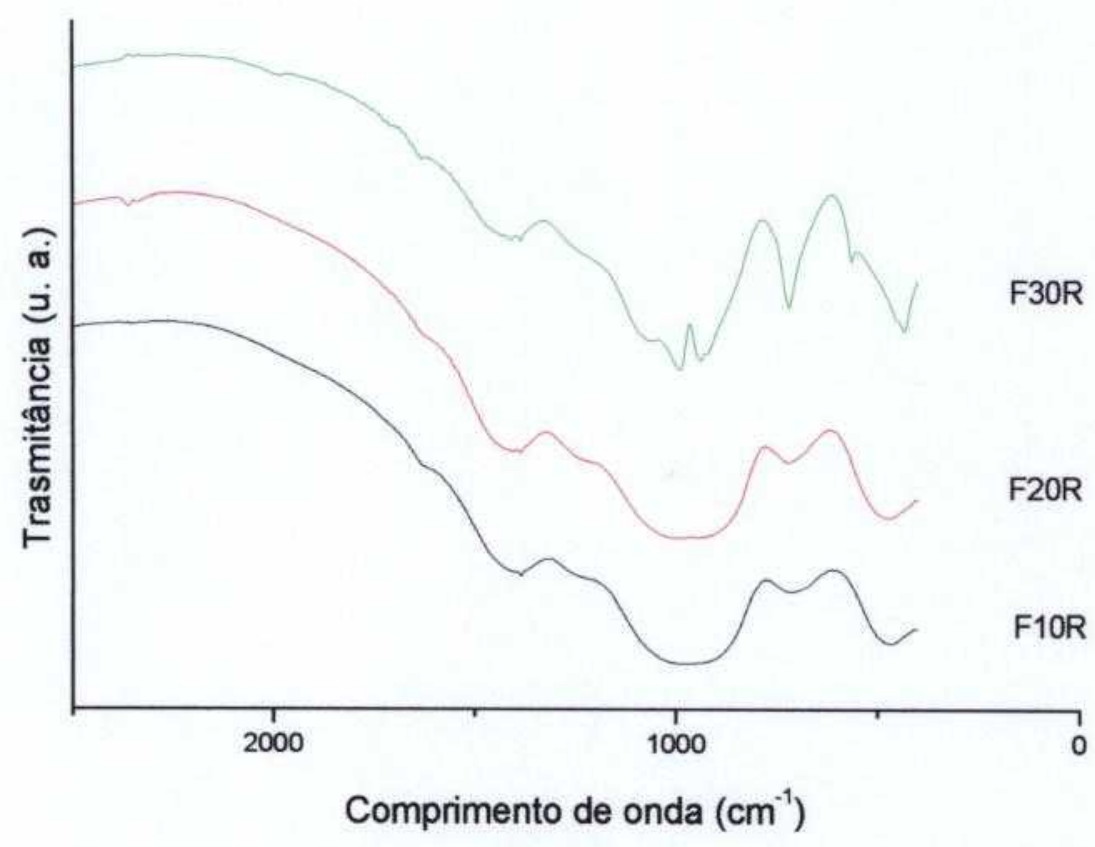

FIGURA 5.17 - Espectros de FTIR das amostras de composições F10R (preto), F20R (vermelho) e F30R (verde).

As análises utilizando-se 0 MEV, realizadas a partir das amostras das composições FR10, FR20 e FR30, ilustrando o aspecto resultante após a fusão e "fritagem" (vertimento em água), mais especificamente, em superfícies de fratura, estão ilustradas na Fig.5.18 a, b e c, respectivamente. Analisando-se a superfície destas fritas não se observa a presença de cristais, revelando características de fratura típica de materiais amorfos, ou seja, sem planos de clivagem e nem de fratura intergranular, confirmando a característica típica amorfa como revelada pelos difratogramas da Figura 5.16. 

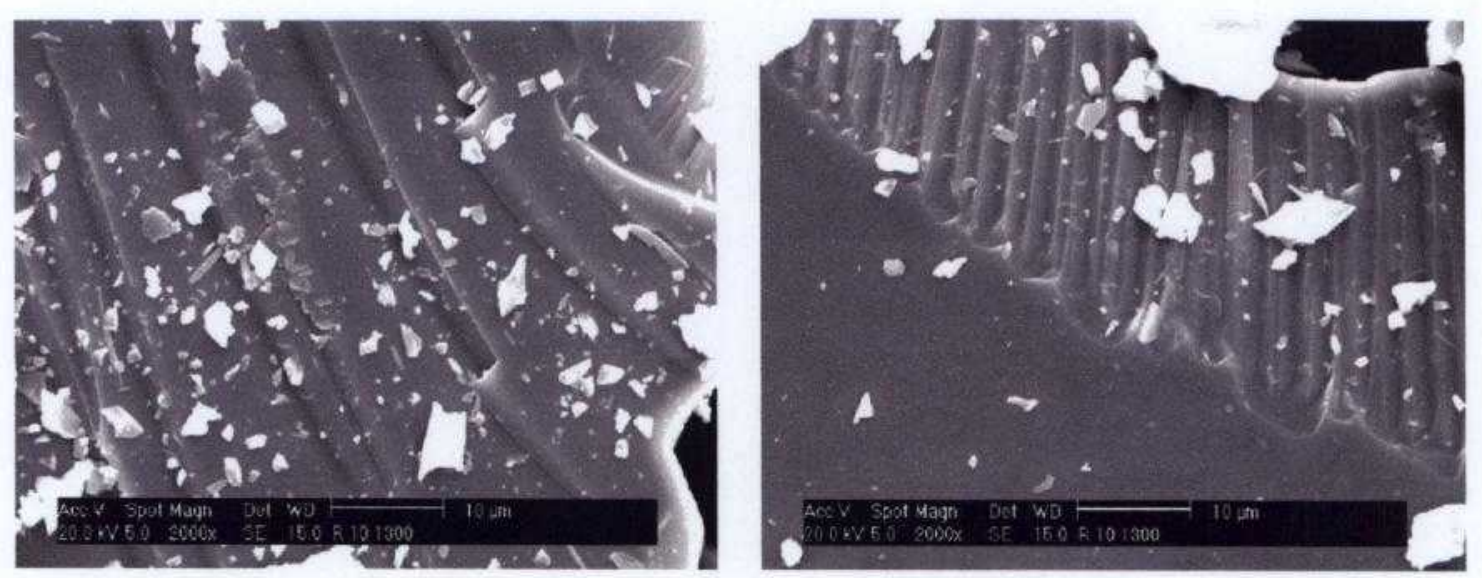

(a)
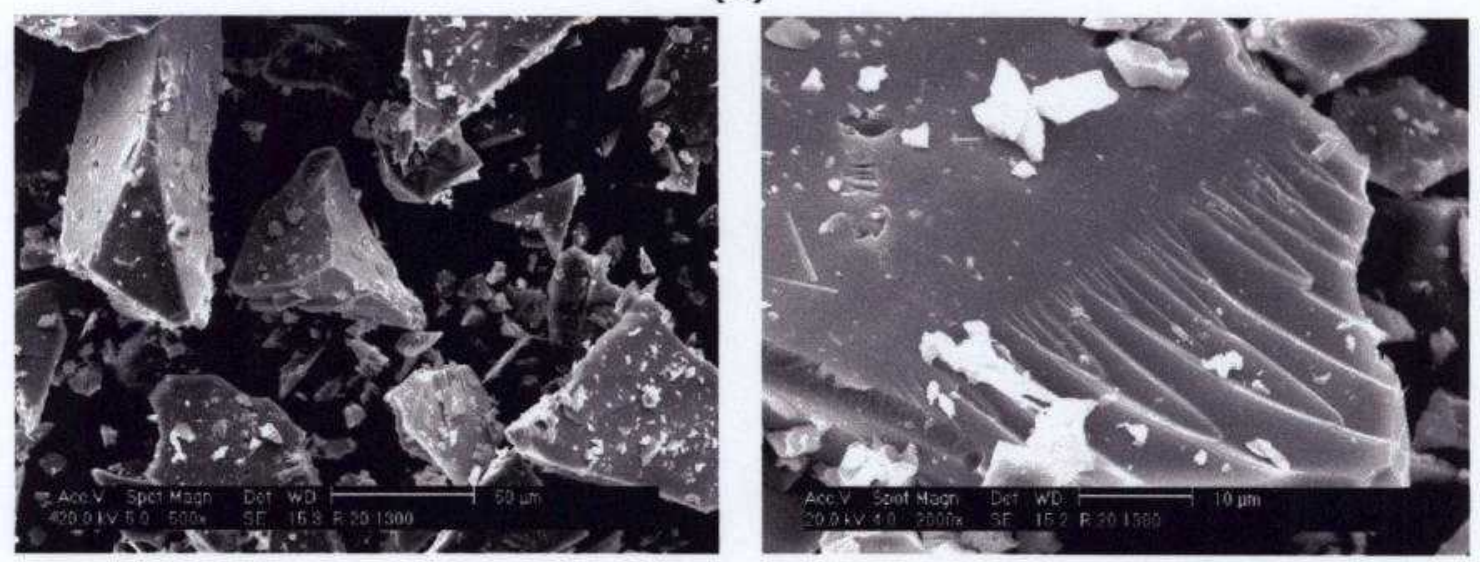

(b)
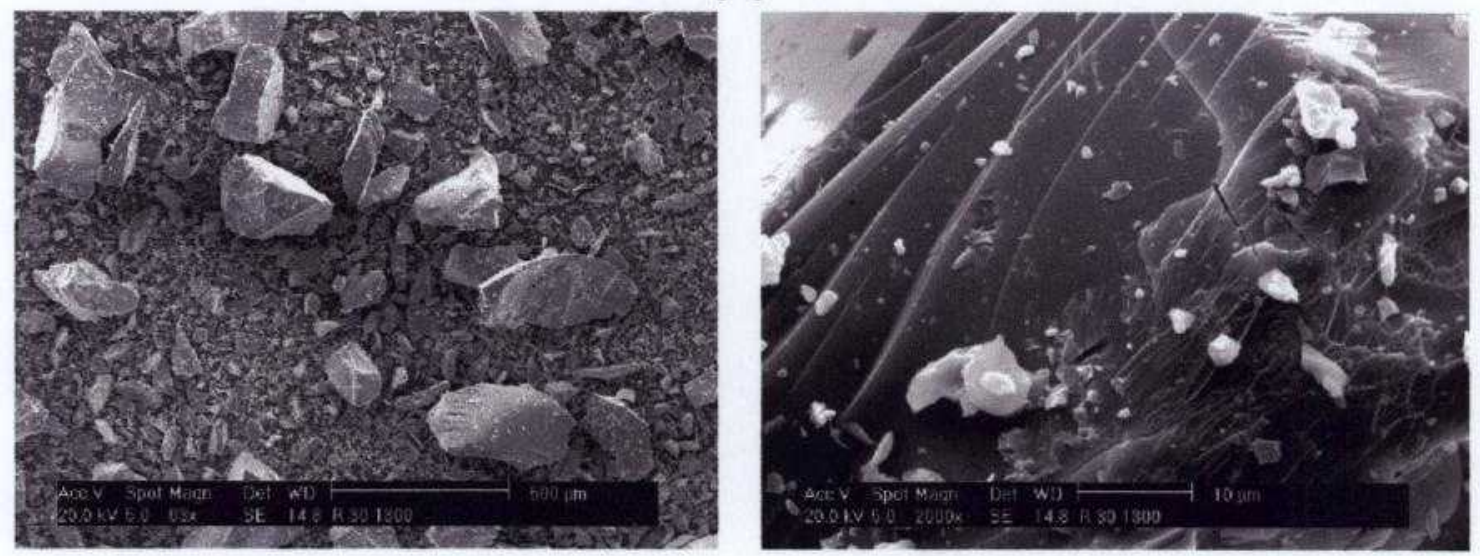

(c)

FIGURA 5.18 - Micrografias das composições com incorporação de resíduo, F10R (a), F20R (b) e F30R (c).

\subsection{Estudo de devitrificação}

Tendo como referência a temperatura de cristalização da frita de $830^{\circ} \mathrm{C}$, ilustrada na FIG.5.12, para os estudos de cristalização das composições obtidas, e, considerando-se as maiores concentrações de alumina, em decorrência da adição do resíduo (TAB. 5.4), utilizou-se a 
temperatura de $900^{\circ} \mathrm{C}$ com patamares de tempo de tratamento de 0,5 ; 1,0 e 2,0 horas.

Os difratogramas resultantes das amostras após os tratamentos térmicos de devitrificação nos vários tempos de tratamento são apresentados nas FIG. 5.17, 5.18 e 5.19, respectivamente, para as composições F10R, F20R e F30R.

Na FIG. 5.17, que corresponde às amostras de composição $\mathrm{F} 10 \mathrm{R}$, observa-se que já a partir de 30 minutos de tratamento a $900^{\circ} \mathrm{C}$, ocorre nucleação de fase cristalina com alguns picos relativos às fases cristalinas, silicato de dicálcio (2 $\mathrm{CaO} \cdot \mathrm{SiO} 2)$ e anortita $\left(\mathrm{CaO} \cdot \mathrm{Al}_{2} \mathrm{O}_{3} \cdot 2 \mathrm{SiO}_{2}\right)$ e em tempos maiores de tratamento, um silicato de cálcio e alumínio $\left(\mathrm{Ca}_{1,82} \mathrm{Al}_{3,64} \mathrm{Si}_{0,36} \mathrm{O}_{8}\right)$, que estão de acordo com o triângulo de compatibilidade do sistema apresentado na FIG. 5.15. O aparecimento destes componentes se acentua à medida que o tempo de permanência nesta temperatura aumenta.

Na FIG. 5.18, onde são apresentados os espectros de difração de raios $X$ para as amostras de composição F20R, observa-se comportamento similar ao da composição anterior, porém, neste caso, as fases cristalinas são predominantes a partir de 30 minutos de tratamento. Neste caso, identificam-se as fases anortita $\left(\mathrm{CaO} \cdot \mathrm{Al}_{2} \mathrm{O}_{3} \cdot 2 \mathrm{SiO}\right)$ e guelenita $\left(2 \mathrm{CaO} \cdot \mathrm{Al}_{2} \mathrm{O}_{3} \cdot \mathrm{SiO}_{2}\right)$ mesmo após 1 ou 2 horas de tratamento térmico é favorecida a cristalização de guelenita como fase principal. 


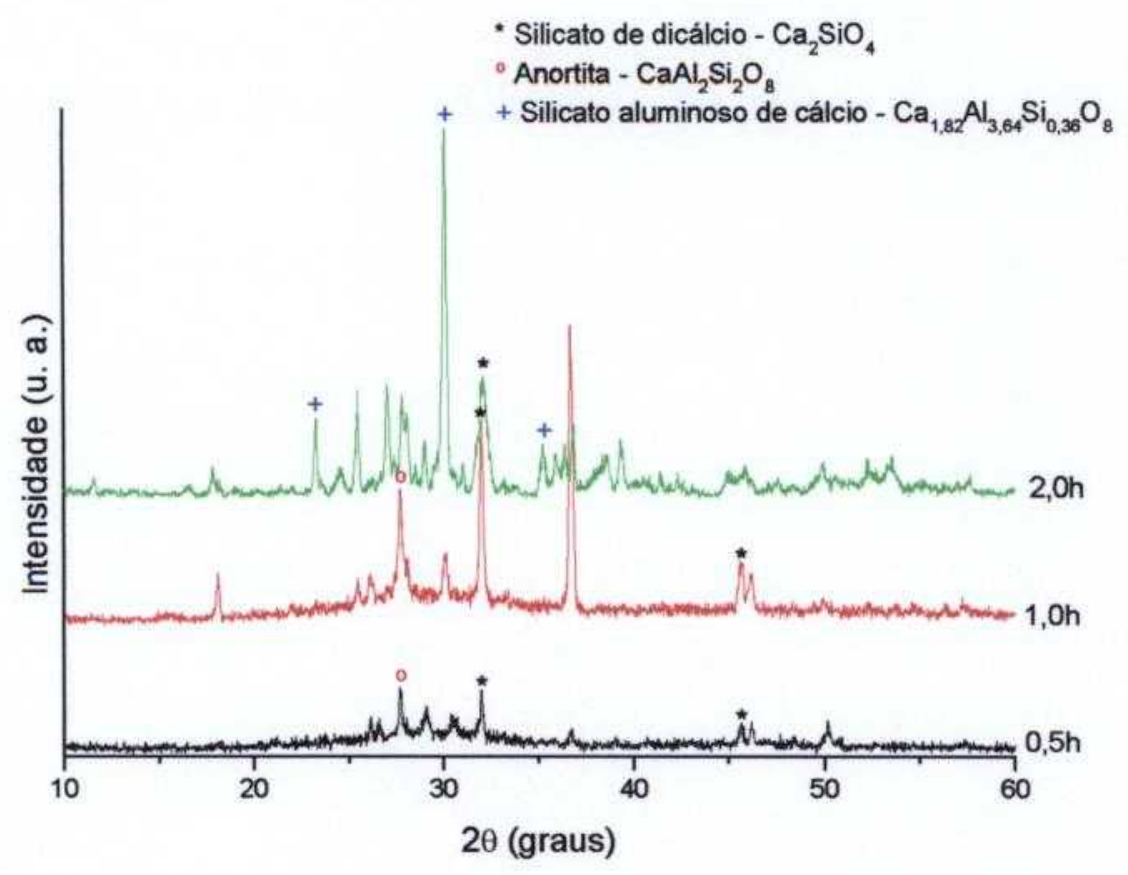

FIGURA 5.17 - Difratograma da composição F10R após tratamento térmico a $900^{\circ} \mathrm{C}$ por 0,5 (preto); 1,0 (vermelho) e 2,0 h (verde).

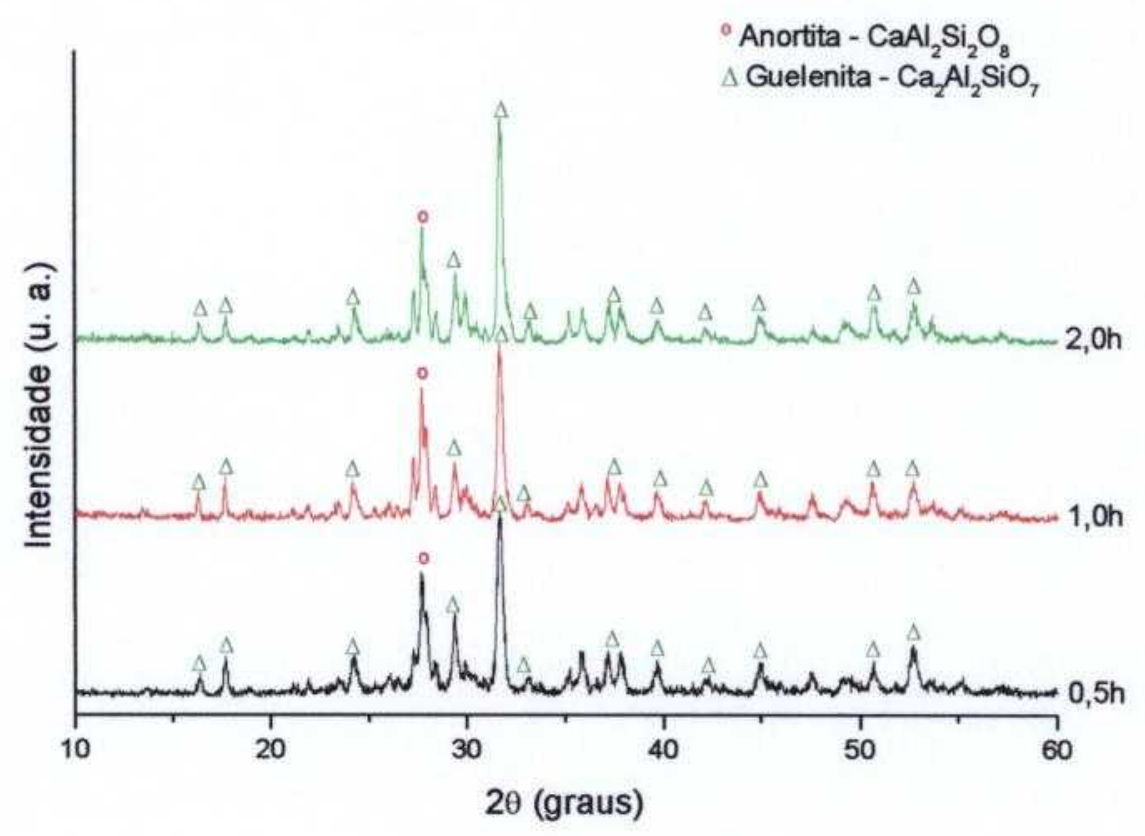

FIGURA 5.18 - Difratograma da composição F20R após tratamento térmico a $900^{\circ} \mathrm{C}$ por 0,5 (preto); 1,0 (vermelho) e 2,0h (verde). 
A FIG. 5.19 apresenta cristalização para a composição F30R no tratamento térmico a $900^{\circ} \mathrm{C}$ por 2 horas; o tratamento por 0,5 e 1,0 hora não foi suficiente para promover cristalização das amostras analisadas. Esta característica era prevista, visto que essa composição está localizada em cima da isoterma de $1500^{\circ} \mathrm{C}$; possivelmente uma fusão em temperaturas mais elevadas facilitaria a cristalização da guelenita.

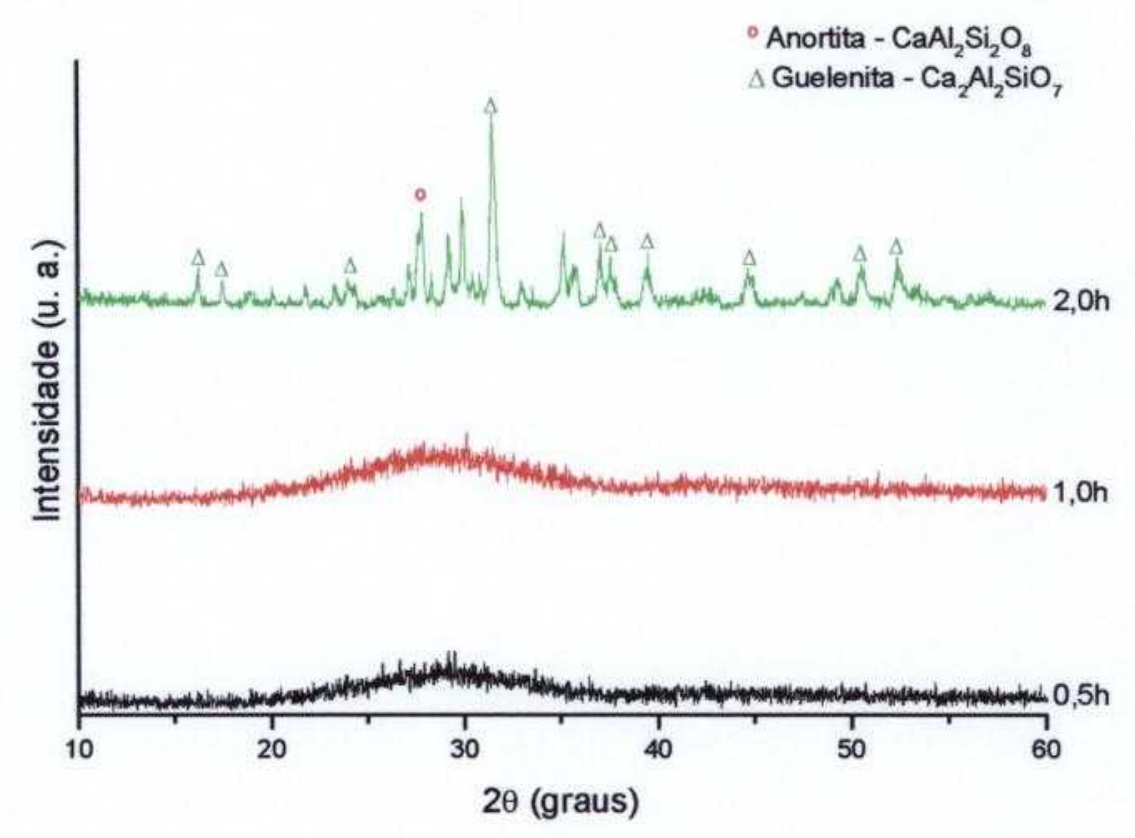

(c)

FIGURA 5.19 - Difratograma das composições F30R após tratamento térmico a $900^{\circ} \mathrm{C}$ por 0,5 (preto); 1,0 (vermelho) e 2,0 h (verde).

As composições $\mathrm{F} 10 \mathrm{R}$, F20R e $\mathrm{F} 30 \mathrm{R}$ tratadas a $900^{\circ} \mathrm{C}$ por 2 horas foram analisadas por MEV para verificação da morfologia e confirmação da cristalização das amostras tratadas termicamente (FIG. 5.20). 

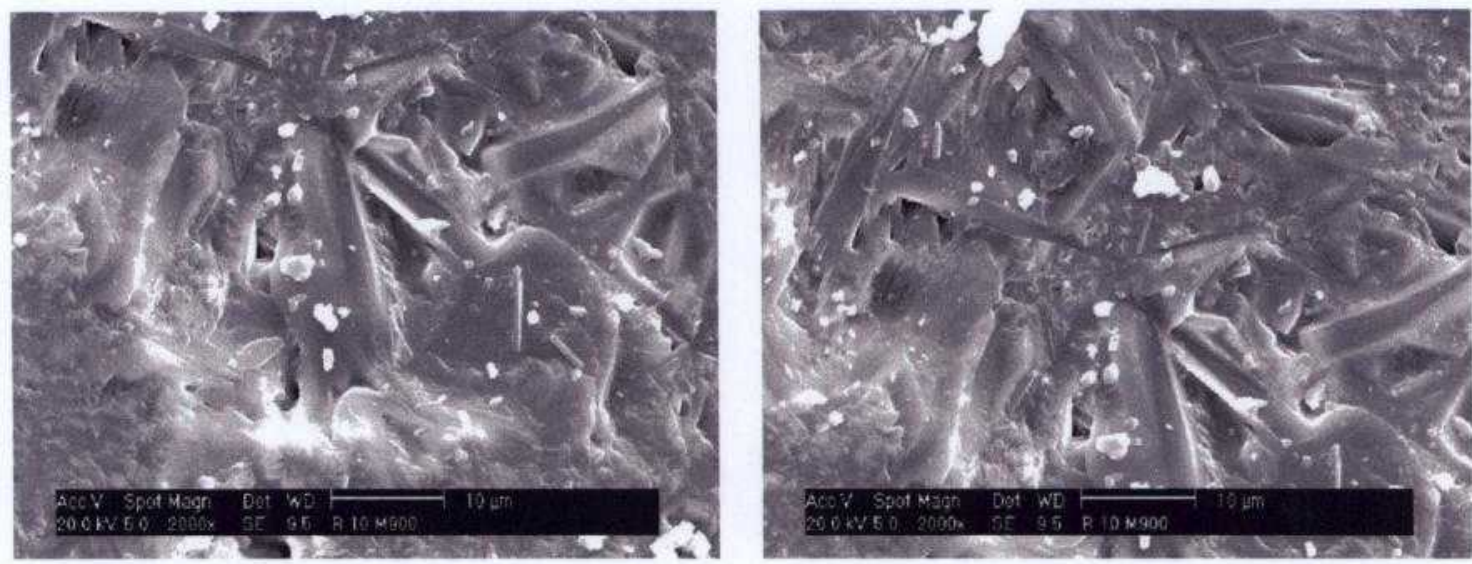

(a)
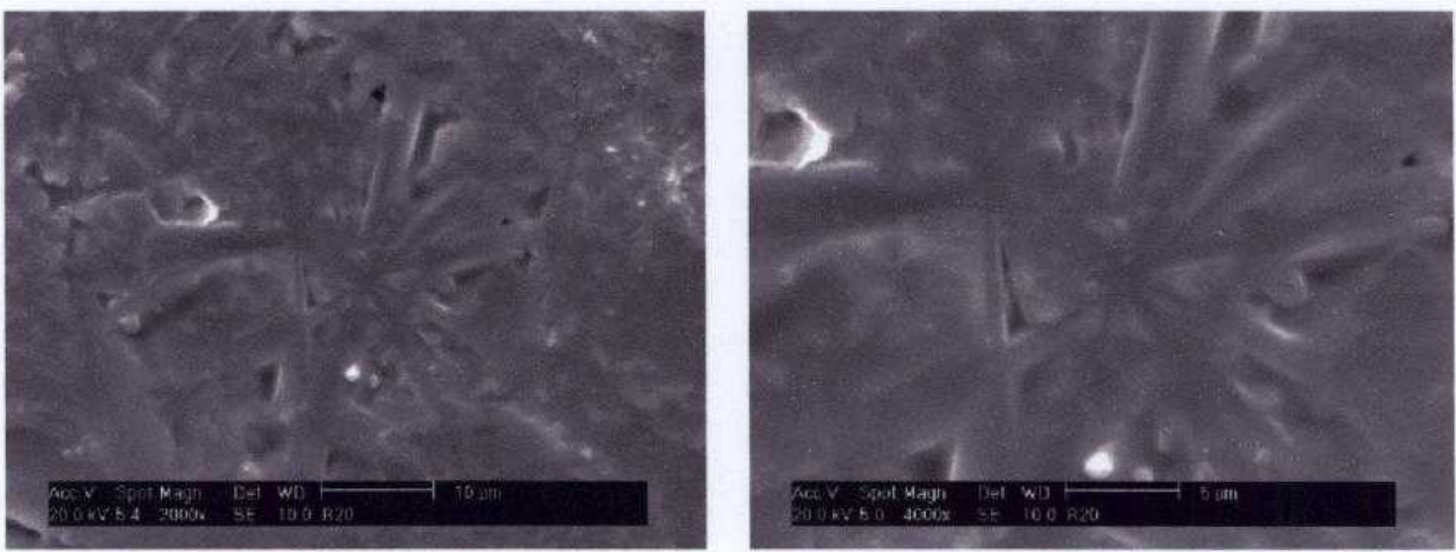

(b)
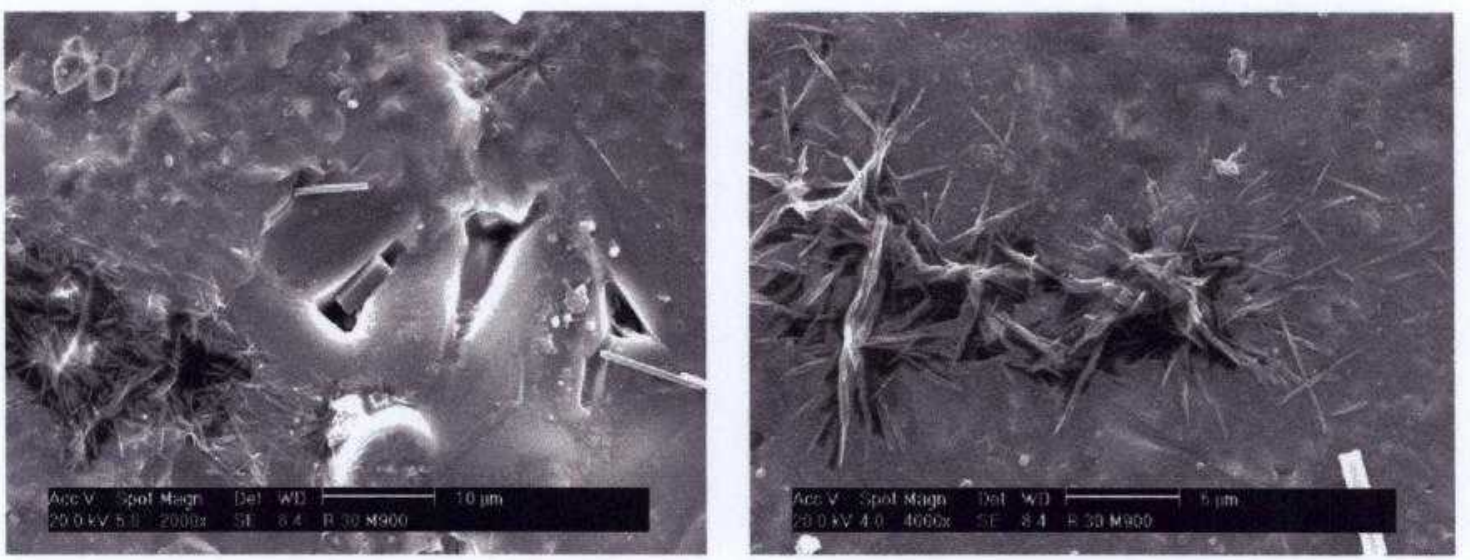

(c)

FIGURA 5.20 - Micrografias das amostras F10R-M900 (a), F20R-M900 (b) e F30R-M900 (c), devitrificadas por duas horas.

As micrografias das análises de MEV apresentam a cristalização esperada nas fritas com adição de resíduo e tratadas termicamente: F10R-M900, F20R-M900 e F30R-M900. Pode-se verificar a nucleação de fases cristalinas em todas as amostras, observando-se cristais nucleando a partir da fase amorfa. 
A amostra F30R-M900 apresenta nucleação de cristais, não são encontrados cristais crescidos, como nas amostras F1OR-M900 e F20R-M900, onde na mesma temperatura utilizada foi possível promover o crescimento dos cristais de guelenita. 


\section{CONCLUSÕES}

- O processo de incorporação do RBB em fritas vitrocerâmicas mostrou ser eficaz contribuindo para desenvolvimento de tecnologias ambientalmente amigáveis baseadas na geração de resíduo zero no processo de obtenção de alumínio metálico por plasma térmico;

- O RBB pode ser incorporado à composição de fritas comerciais até a concentração de $30 \%$ em massa, sem alterar o comportamento de vertimento da frita durante o processo de fabricação da mesma;

- A fusão da frita com resíduo a $1300^{\circ} \mathrm{C}$ permitiu a obtenção de um vidro silicato com alto teor de resíduo adicionado;

- A concentração máxima de resíduo adicionado não interferiu na formação de fases cristalinas durante o processo de devitrificação;

- A presença do resíduo com alta concentração de alumínio é um facilitador na formação de fases cristalinas na matriz amorfa do vidro;

- Os tratamentos térmicos de devitrificação realizados a $900^{\circ} \mathrm{C}$ promoveram a formação de vitrocerâmicos apresentando como fases cristalinas predominantes a volastonita, anortita e guelenita, de acordo com os triângulos de compatibilidade de fases pertencentes ao diagrama de equilíbrio do sistema $\mathrm{Al}_{2} \mathrm{O}_{3}-\mathrm{CaO}-\mathrm{SiO}_{2}$. 


\section{SUGESTÕES PARA TRABALHOS FUTUROS}

- Caracterizar os vidros obtidos com incorporação de resíduo após fusão a $1300^{\circ} \mathrm{C}$;

- Estudar a influência das adições de resíduo no comportamento mecânico e nas características de superfície dos esmaltes preparados a partir das fritas com adição de resíduo e tratadas termicamente;

- Estabelecer o mecanismo de cristalização da frita com incorporação de resíduo envolvendo aspectos cinéticos;

- Verificar a possibilidade de realizar um único tratamento térmico de fusão e devitrificação das composições com adição de resíduo;

- Comparar as composições estudadas com formulações obtidas a partir de óxidos puros. 


\section{REFERÊNCIAS BIBLIOGRÁFICAS}

ABAL; "Associação Brasileira do Alumínio"; http://www.abal.org.br, consultado em fevereiro de 2005.

ABNT; Associação Brasileira de Normas Técnicas - 2004a. NBR 10.004 resíduos sólidos - Classificação. Rio de Janeiro, Brasil.

ALBARO, J. L. A.; "Glazes for Ceramic Wall and floor Tiles: Evolution and Perspectives"; Tile and Brick Institute; 9 (5); (1993).

ALVAREZ-MÉnDEZ, A.; et al.; "Kinetic thermal analysis of glass ceramics from industrial wastes"; Journal of Non-Crystalline Solids; 329; p: 73 - 76; (2003).

ANDREOLA, F.; BARBIERI, L.; et al.; "Physical-chemical characterization of a galvanic sludge and its inertization by vitrification using container glass"; Waste Management and the Environment III; In: THIRD INTERNATIONAL CONFERENCE ON WASTE MANAGEMENT AND THE ENVIRONMENT; June 21 - 23; Malta. Proceedings...Malta: WIT Press, 2006. p. .

ATWOOD, D. A.; YEARWOOD, B. C.; "The Future of Aluminum Chemistry"; Journal of Organometallic Chemistry; 600; p: 186 197; (2000).

AZOM, "The $A$ to $Z$ of Materials"; http://www.azom.com., consulta realizada em julho de 2005.

BARBIERI, L.; BONAMARTINI, A. C.; LANCELLOTTI, I.; "Alkaline and Alkaline-earth Silicate Glasses and Glass-ceramics from Municipal and Industrial Wastes"; Journal of the European Ceramic Society; 20; p: 2477 - 2483; (2000). 
BARBIERI, L.; LANCELLOTTI, I.; "Design, Obtainment and Properties of Glasses and Glass-ceramics from Coal Fly Ash"; Fuel Elsevier; 78; p: 271 - 276; (1999).

BARBIERI, L.; CORRADI, A.; LANCELlOTTI, I.; PELLACANI, G. C.; "Sintering and crystallization behaviour of glass frits made from silicate wastes"; Glass Technology; 44; p: 184 - 190; (2003).

BOCCACCINI, A. R.; KÖPF \& W. STUMPFE, M.; "Glass-ceramics from filter dusts from waste incinerators"; Ceramics International; 21; p: 231 - 235; (1995).

BORgeRON, C. J.; RISBUD, S. H.; "Introduction to Phase Equilibria in Ceramics"; University of Illinois; The American Ceramic Society Inc.; (1984).

CAMPANILI, M.; "Jornal O Estado de São Paulo"; 02 de maio de 2002.

Cheng, T. W.; Weng, T. H.; CHEN, Y. S.; CHIU, J. P.; "Production of glass-ceramic from incinerator fly ash"; Ceramics International; 28; p: 779 - 783; (2002).

CIMDINS, R.; et al.; "Glassceramics obtained from industrial wastes"; Resources, Conservation and Recycling; 29; p: 285 - 290; (2000).

CONSTANTINO, V. R. L., ARAKI, K., SILVA, D. O., OLIVEIRA, W.; "Preparação de compostos de alumínio a partir da bauxita: considerações sobre alguns aspectos envolvidos em um experimento didático"; Química Nova; 25 (3); p: 1 - 20; (2002).

CORDELAN, J.; et al.; "FE Modelling of Strengthening of High Glass Containing Silicate Ceramics (Vitroceramics)"; Berichte der Deutschen Keramischen Gesellschaft; 78 (6); p: E-38 - E-40; (2001).

COURTENAY, J. H.; "The influence of the content of magnesium chloride in fused refining agents"; The Melt Quality Partnership (2005). 
DUAN, R. G.; LIANG, K. M.; "A Study of the crystallization of CaO$\mathrm{Al}_{2} \mathrm{O}_{3}-\mathrm{SiO}_{2}$ system glasses"; Journal of Mat. Proc. Technology; 75; $\mathrm{p}$ : 235 - 239; (1998-A).

DUAN, R. G.; LIANG, K. M.; GU, S. R.; "Effect of changing $\mathrm{TiO}_{2}$ content on structure and crystallization of $\mathrm{CaO}-\mathrm{Al}_{2} \mathrm{O}_{3}-\mathrm{SiO}_{2}$ system glasses"; Journal of the European Ceramic Society; 18; p: 1729 1735; (1998-B).

DUAN, R. G.; LIANG, K. M.; GU, S. R.; "A study on the mecanism of crystal growth in the process of crystallization of glasses"; Materials Research Bulletin; 33; p: 1143 - 1149; (1998-C).

DUNN, J. G.; "Recommendations for reporting thermal analysis data"; Thermochimica Acta; 390; p: 1 - 3; (2002).

ENDO, H.; NAGAYOSHI, Y.; SUZUKI, K; "Production of Glass Ceramics from Sewage Sludge"; Wat. Sci. Technology; 36 (11); p: 235 - 241; (1997).

ESCARDINO, A.; MORENO, A.; IBÁÑEZ, M. J.; BARBA, A.; "Relación entre las Propriedades Mecánicas de Vidriados Cerámicos y su Resistencia al Desgaste"; Boletin de la Sociedad Española de Cerámica y Vidro"; 39 (2); p: 209 - 214; Marzo/Abril de 2000.

FERRARIS, M.; SALVO, M.; et al.; "Glass Matrix Composites from Solid Waste Materials"; Journal of the European Ceramic Society; 21; p: $453-460 ;(2001)$.

FLOHR, L. et Al.; "Classificação de resíduos sólidos industriais com base em testes ecotoxicológicos utilizando Daphnia magna: uma alternativa"; Biotemas; 18 (2); p: 7 - 18; (2005).

FONSECA, M. V. A.; "Reciclagem de Rejeitos Sólidos: Desenvolvimento em Escala de Laboratório de Materiais Vítreos a Partir do Xisto Retordado de São Mateus do Sul - PR"; Tese à USP para Título de Doutor em Engenharia; São Paulo; (1990).

FRADE, J. R.; QUEIROZ, C. M.; FERNANDES, M. H.; "Re-examination of effects of nucleation temperature and time on glass 
MADONO, M.; RACHER, R. P.; KUNKA, M. K.; Alcoa Industrial Chemicals; "American Ceramic Soc. Bull."; 17 (6); p: 82 - 85; June of 1998.

MÁRTIRES, R. A. C.; "Alumínio"; Balanço Mineral Brasileiro; DNPM Departamento Nacional de Produção Mineral; p: 1 - 31; (2001).

MMA; "Ministério do Meio-ambiente"; http://www.mma.gov.br. Consulta realizada em junho de 2005.

NAVARRO, J. M. F.; "El Vidrio"; Consejo Superior de Investigaciones Cientificas; Fundacion Centro Nacional del Vidrio; (1991).

PASCUAL, M. J.; PASCUAL, A. D.; "Vidrios y vitrocerámicos para Soldadura: Usos Tradicionales y Nuevas Áreas de Aplicación"; Consejo Superior de Inestigaciones Cientificas; Instituto de Ceramica y Vidro; Revistas; p: 53 - 68; (1997).

PANNHORST, W.; "Glass-ceramics: State of the Art"; Journal of Non-Crystalline Solids; 219; p: 198 - 204; (1997).

PARK, Y. J.; HEO, J.; "Conversion to glass-ceramic from glasses made by MSW incinerator fly ash for recycling"; Ceramics International; 28; p: 689 - 694; (2002).

PAUL, A.; "Chemistry of Glasses"; Chapman and Hall; New York; (1982).

PeNG, F.; LIANG, K. M.; SHAO, H.; HU, A. M.; "Nano-crystal glassceramics obtained by crystallization of vitrified red mud"; Chemosphere; 59; p: 899 - 903; (2005).

PÉREZ, M. R.; "Procesado y Caracterización de Nuevos Vidrios y Materiales Vitrocerámicos Obtenidos por Residuos Industriales de Geothita"; Boletin de la Sociedad Española de Cerámica y Vidrio; 35 (1); p: 127 - 128; (1996).

RAWLINGS, R. D.; BOCCACCINI, A. R.;"Crystallization and sintering of frits obtained from silicate wastes"; Glass Technology; 45; $\mathrm{p}: 108$ - 111; (2004). 
RICCI, D. R.; AMBRóZIO FILHO, F,; "Caracterização de pós utilizando-se métodos de determinação de tamanho médio de partículas"; Cerâmica; 30; p: 337 - 346; (1984).

RINCón, J. Ma.; ROMERO, M.; MARCO, J.; CABALLER, V.; "Some aspects of crystallization microstructure on new glass-ceramic glazes"; Materials Research Bulletin; 33; p: 1159 - 1164; (1998).

ROCCA, A.C.C., IACOVOME, A.M.M.B.; BARROTI, A.J., et al.; "Resíduos Sólidos Industriais", CETESB; São Paulo; (1993).

ROMERO, M.; RAWLINGS, R. D.; RINCÓN, J. Ma.; "Crystal nucleation and growth in glasses from inorganic wastes from urban incineration"; Journal of Non-Crystalline Solids; 271; p: $106-118$; (2000).

ROMERO, M.; RINCÓN, J. Ma.; et al.; "Use of Vitrified Urban Incinerator Waste as Raw Material for Production of Sintered Glassceramics"; Materials Research Bulletin; 36; p: 383 - 395; (2001).

Roskosz, M.; TOPLIS, M. J.; BESSON, P.; RICHET, P.; "Nucleation mechanisms: A crystal-chemical investigation of phases forming in highly supercooled aluminosilicate liquids"; Journal of Non-Crystalline Solids; 351; p: 1266 - 1282; (2005).

SCHICHT, H.; EMONDS, M.; ESSER, J.; "Pin-pointed Modification of Glass Surfaces by Using Specific Washing Compounds"; Journal of Non-Crystalline Solids; 218; p: 210 - 217; (1997).

SENAI, Ecolife; "Controle Ambiental - Tratamento e Recuperação de Despejos Industriais"; (1995).

SHINZATO, M. C., HYPOLITO, R.; "Solid Waste from aluminum recycling process: characterization and reuse of its economically valuable constituents"; Waste Management; 25; p: 37 - 46; (2005). SIGOLI, F. A.; KAWANO, Y.; DAVOLOS, M. R.; FAFELICCI JR., M.; "Phase separation in pyrex glass by hydrothermal treatment: evidence from micro-Raman spectrscopy"; Journal of Non-Crystalline Solids; 284; p: 49-54; (2001). 
SUSLICK, S. B.; "Previsão de Consumo de Alumínio Metálico no Brasil..."; Revista Brasileira de Geociências; 21 (3); p: 275 - 284; Setembro de (1991).

SZABó, I.; "Crystallization of magnesium aluminossilicate glasses"; Journal of Non-Crystalline Solids; 219; p: 128 - 135; (1997).

TANAKA, M.; "CaO-Al $\mathrm{O}_{3}-\mathrm{SiO}_{2}$ Glass-ceramics of the composition based on inorganic wastes"; Journal of the Ceramic society of Japan; 112 (12); p: 655 - 660; (2004).

TORRES, F. J.; ALARCÓN, J.; "Effect of additives on the crystallization of cordierite-based glass-ceramics as glazes for floor tiles"; Journal of the European Ceramic Society; 23, p: $817-826$; (2003).

TUlyaganOV, D. U.; RIBEIRO, M. J.; LABRINCHA, J. A.; "Development of glass-ceramics by sintering and crystallization of fine powders of calcium-magnesium-aluminossilicate glass"; Ceramics International; 28; p: 515 - 520; (2002).

UFRGS, "Universidade Federal do Rio Grande do Sul", http://www.ufrgs.br. Com sultado em maio de 2006.

UFRJ, "Universidade Federal do Rio de Janeiro"; http://www.ufrj.br. USGS; "Unites States Geological Survey"; http://www.usgs.gov. 
Instituto de Pesquisas Energéticas e Nucleares

Diretoria de Pesquisa, Desenvolvimento e Ensino

Av. Prof. Lineu Prestes, 2242 Cidade Universitária CEP: 05508-000

Fone/Fax(0XX11) $3816-9148$

SAO PAULO - Săo Paulo - Brasil

http: //www.ipen.br

O Ipen 6 uma autarqula vinculada a Secretaria de Clencia, Tecnologla o Decenvolvimento Economico - Turismo do Eatado do Sto Pauto, gerlda tocnica, administrattva ef financeiramente pela

Comlasto Maclonal do Energia Nuciear, orgto do Miniattrio da Ciencla e

Tecnologia, o aseoctada in Unlverskdado de Sto Paulo. 